\title{
Review: Using physiologically based models to predict population responses to phytochemicals by wild vertebrate herbivores
}

\author{
J. S. Forbey ${ }^{1 \dagger}$, R. Liư ${ }^{2}$, T. T. Caughlin ${ }^{1}$, M. D. Matocq ${ }^{3}$, J. A. Vucetich ${ }^{4}$, K. D. Kohl', \\ M. D. Dearing ${ }^{6}$ and A. M. Felton
}

\begin{abstract}
${ }^{1}$ Department of Biological Sciences, Boise State University, Boise, ID 83725, USA; ${ }^{2}$ Department of Mathematics, University of Wyoming, Laramie, WY 82071, USA; ${ }^{3}$ Program in Ecology, Evolution, and Conservation Biology, Department of Natural Resources and Environmental Science, University of Nevada, Reno, NV 89557, USA; ${ }^{4}$ School of Forest Resources and Environmental Science, Michigan Technological University, Houghton, MI 49931, USA; ${ }^{5}$ Department of Biological Sciences, University of Pittsburgh, 4249 Fifth Ave., Pittsburgh, PA 15260, USA; ' ${ }^{6}$ Department of Biology, School of Biological Sciences, University of Utah, 257 South 1400 East, Salt Lake City, UT 84112, USA; ${ }^{7}$ Southern Swedish Forest Research Centre, Faculty of Forest Sciences, Swedish University of Agricultural Sciences, P.O. Box 49, Alnarp SE-230 53, Sweden
\end{abstract}

(Received 30 May 2018; Accepted 2 August 2018; First published online 25 September 2018)

To understand how foraging decisions impact individual fitness of herbivores, nutritional ecologists must consider the complex in vivo dynamics of nutrient-nutrient interactions and nutrient-toxin interactions associated with foraging. Mathematical modeling has long been used to make foraging predictions (e.g. optimal foraging theory) but has largely been restricted to a single currency (e.g. energy) or using simple indices of nutrition (e.g. fecal nitrogen) without full consideration of physiologically based interactions among numerous co-ingested phytochemicals. Here, we describe a physiologically based model (PBM) that provides a mechanistic link between foraging decisions and demographic consequences. Including physiological mechanisms of absorption, digestion and metabolism of phytochemicals in PBMs allows us to estimate concentrations of ingested and interacting phytochemicals in the body. Estimated phytochemical concentrations more accurately link intake of phytochemicals to changes in individual fitness than measures of intake alone. Further, we illustrate how estimated physiological parameters can be integrated with the geometric framework of nutrition and into integral projection models and agent-based models to predict fitness and population responses of vertebrate herbivores to ingested phytochemicals. The PBMs will improve our ability to understand the foraging decisions of vertebrate herbivores and consequences of those decisions and may help identify key physiological mechanisms that underlie dietbased ecological adaptations.

Keywords: foraging ecology, geometric framework, physiology, phytochemicals, modeling

\section{Implications}

Food intake by wild herbivores shapes the distribution of both plants and animals across the globe. The use of physiologically based models (PBMs) will help formalize the link between phytochemical consumption and population demography for vertebrate herbivores. Understanding and predicting demographic outcomes of foraging is critical for effective wildlife management, especially in light of rapidly changing food availability and quality across landscapes.

\section{Introduction}

A central focus in the field of foraging ecology is to understand how diet quality influences the behavior, distribution

${ }^{\dagger}$ E-mail: jenniferforbey@boisestate.edu and population dynamics of animals. For vertebrate herbivores, the quality and quantity of phytochemicals (both nutrients and toxins) in foods can significantly alter the foraging behavior, physiology and growth of both captive (Dearing et al., 2002; Sorensen et al., 2005b; Marsh et al., 2006) and free-ranging individuals (DeGabriel et al., 2009; Moore et al., 2010; Frye et al., 2013; Stolter et al., 2013; Ulappa et al., 2014). Captive studies have established causal relationships between phytochemicals and foraging (Wiggins et al., 2003; McLean et al., 2007; Kirmani et al., 2010; Torregrossa et al., 2012; Shipley et al., 2012) and individual demographic outcomes such as changes in energy budgets, body mass or survival (Sorensen et al., 2005b; Kohl et al., 2014 and 2016b). These studies generally focus on single phytochemicals as an analog for whole plants (Wiggins et al., 2003; McLean et al., 2007; Kirmani et al., 2010; Shipley et al., 2012) and often do not capture the phytochemical 
complexity of herbivores foraging in landscapes with diverse plant communities.

In the 1950s and the decades following, it was common in studies of free-ranging vertebrate herbivores to measure a single currency (often energy) and use mathematical modeling to make foraging and demographic predictions based on that currency (e.g. optimal foraging theory: Emlen, 1966; MacArthur and Pianka, 1966; Schoener, 1971; Charnov, 1976; Pyke et al., 1977; Belovsky, 1978; dynamic energy budget (DEB) theory: Kooijman and Metz, 1984; Nisbet et al., 2000; adaptive herbivore ecology: Owen-Smith, 2002 and 2004). Since then, we have gained knowledge of the complexity of interacting phytochemicals, and the importance of assessing multiple constituents at the same time (e.g. ecological stoichiometry: Muller et al. 2001; Moe et al., 2005; geometric framework (GF): Simpson and Raubenheimer, 1993 and 2001; Raubenheimer and Simpson, 1998). Field studies on vertebrate herbivores have increasingly incorporated aspects of complex phytochemicals inherent in natural systems when assessing links to population demography (Rode and Robbins, 2000; Wam et al., 2018). However, field studies often provide only correlative links between phytochemicals and demographic parameters. As a consequence, we lack a mechanistic understanding how the capacity to process phytochemicals by individual herbivores (e.g. Solon-Biet et al., 2014; Simpson et al., 2017) translates to changes in nutritional condition (Parikh et al., 2017), reproduction (Brittas, 1988; DeGabriel et al., 2009), survival (Wing and Messmer, 2016) or population density (Fauchald et al., 2017) of free-ranging vertebrates. Theoretical advances have attempted to use estimates of individual physiological responses to toxic phytochemicals in order to link browsing to population stability of vertebrate herbivores (Feng et al., 2009; Liu et al., 2012). However, these approaches are limited by a lack of empirical physiological data required to test and refine the parameters that underlie demographic models of wild herbivores consuming complex phytochemicals.

A key to linking foraging behavior to demography is greater ability to predict variation in the physiological consequences of consuming phytochemicals among individuals, among populations within a species (biogeographic variation) and among species (evolutionary variation). The paucity of genomic data for non-model, wild vertebrate herbivores continues to be a critical barrier (although see Ge et al., 2013; Zhao et al., 2013; Campbell et al., 2016; Gordon et al., 2016). The application of functional genomic analyses to wild invertebrate systems demonstrates the great promise for identifying physiological tolerance to phytochemicals (Li et al., 2017; Snoeck et al., 2017), but such applications are still in their earliest stages for vertebrates (Campbell et al., 2016; Kohl et al., 2016a). In addition, relatively diverse foraging behaviors associated with long life spans and wide geographic dispersal potential of vertebrates often confound the ability to mechanistically link foraging behavior with physiological mechanisms and demographic consequences (Forbey et al., 2013; DeGabriel et al., 2014).
We propose that PBMs, particularly those developed in modern biomedical research, provide the needed framework to generate physiological data that can strengthen existing ecological approaches used to predict demographic consequences of plant-herbivore interactions (Figure 1). Specifically, the field of pharmacology has developed PBMs designed to predict the effectiveness and health consequences of pharmaceuticals and nutraceuticals in humans (Esch et al., 2015; Sager et al., 2015; Ting et al., 2015; Tsamandouras et al., 2015). These PBMs use data on molecular expression and physiological function of proteins in the body of consumers to predict what the body does to ingested drugs or nutrients (pharmacokinetics) and what the resultant concentrations of drugs or nutrients do to the body (pharmacodynamics). One objective of PBMs is 'personalized pharmacology,' where genetic variation (sequence and expression) of the proteins that absorb, metabolize or bind to specific chemical structures is used to determine the optimal combination and concentration of drugs and nutrients that elicit desired changes in cellular function, body mass and survival (Alyass et al., 2015; Locke et al., 2015; Wang et al., 2015; Bray et al., 2016; Rao et al., 2017). The result is an accurate prediction of human health at the individual level based on how genes govern the physiological response to ingested chemicals. Similarly, we propose that PBMs could increase the knowledge of physiological interactions between herbivores and ingested phytochemicals to more accurately predict fitness outcomes.

Although existing PBMs in humans typically focus on predicting responses to a single drug, there is increased interest to predict health responses to drug-drug and drugherb interactions (Mano et al., 2015; Zhao et al., 2011; Gurley et al., 2017; Lepist and Ray, 2017). Similarly, the GF for nutrition provides an analytical framework that considers fitness responses to the multi-dimensional phytochemical environment consumed by herbivores. The underlying idea behind this framework is that the ingestion of one dietary item can affect the ingestion or digestion of another (Simpson and Raubenheimer, 2012). For example, the effects of a toxin on an animal's physiology may be intricately linked to the relative balance of nutrients in the food (Villalba and Provenza, 2005; Au et al., 2013). The GF provides an analytical construct that can empirically deal with several phytochemical currencies at the same time, to describe, understand, and predict foraging and fitness outcomes of individuals and groups of animals (Simpson and Raubenheimer, 2012). The focus of the GF is on observing the choices that individuals make when faced with different dietary options within a nutritional, multi-dimensional, space to identify patterns of diet selection without a priori assumptions as to what may be guiding that selection. The GF has revealed that the degree to which animals can regulate their intake of multiple nutrients results in a balance (or imbalance) among nutrients that can have demographic consequences (Solon-Biet et al., 2014; Simpson et al., 2017). Geometric framework links multidimensional nutrient intake to fitness, and was initially 


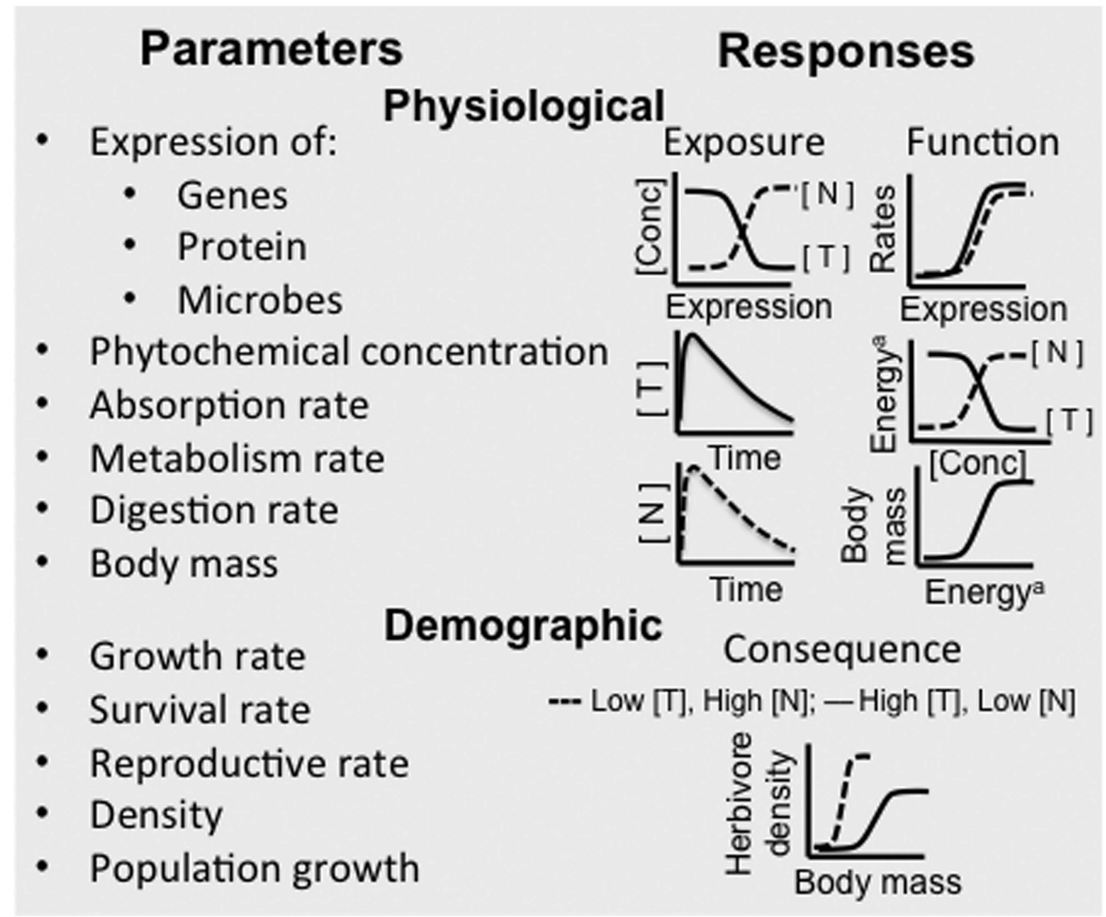

Figure 1 Overview illustrating the relationship between physiological and demographic parameters that can predict physiological and demographic responses in vertebrate herbivores consuming phytochemicals. Key physiological responses include exposure (concentration [Conc]-time course) to both toxic $[\mathrm{T}]$ and nutrient $[\mathrm{N}]$ phytochemicals based on the expression of genes, proteins and microbes, and functional changes in rates of absorption, digestion, and metabolism of toxin and nutrients that result in concentration-dependent changes in available energy that links to body mass and density of herbivores. ${ }^{\text {a}}$ Energy represents one example of a predicted currency that is influenced by toxin and nutrient exposure in the body of a theoretical herbivore (systemic concentration over time) that can link to body mass and demographic parameters.

demonstrated in invertebrate species (Simpson and Raubenheimer, 1993 and 2001). More recently, this framework has been applied to both captive (Sørensen et al., 2008; Hewson-Hughes et al., 2011 and 2012; Solon-Biet et al., 2014; Felton et al., 2016; Simpson et al., 2017) and free-ranging (Rode and Robbins, 2000; Felton et al., 2009; Rothman et al., 2011; Machovsky-Capuska et al., 2016) vertebrates. Extensive work on the mouse (Mus musculus) under a wide range of dietary conditions demonstrates how the ratios of multiple nutrients consumed directly alters life history traits and metabolic function of individuals (Simpson et al., 2017). As demonstrated in invertebrates, post-ingestive absorption and use of nutrients can be accounted for in GF models to explain metabolic and fitness costs of diets (Simpson and Raubenheimer, 2001). One important application of GF is an increased capacity to manage fitness through the regulation of nutrient balances. Physiologically based model have potential to aid in GF outcomes by identifying and quantifying the physiological mechanism that increase or decrease the assimilation and concentrations of ingested nutrients within the body compartments of individuals.

Here we describe how PBMs can be used to predict individual variation in phytochemical exposure based on the absorption and metabolism of ingested phytochemicals (kinetics) and nutritional consequences based on concentration-dependent physiological effects of ingested phytochemicals (dynamics). It is important to note that the
PBMs we describe focus on predictions made after the animal has selected a food item. In other words, PBMs do not address the complexities of food preferences and other behavioral aspects of food selection (Shipley et al., 1999; Felton et al., 2018). Instead, we focus on how PBMs can be used to explain variation in physiological parameters that are a consequence of food selection. In addition, we show how PBMs can leverage the GF to treat intake and post-ingestive physiological processes as an integrated system (Raubenheimer and Simpson, 1998; Simpson and Raubenheimer, 2001) to better predict individual fitness and population-level demographic outcomes. For example, PBMs can predict changes in nutrient assimilation based on known individual variation in genetically determined capacity to detoxify toxins that inhibit digestion and metabolism of nutrients. When applied to GF modeling, knowledge of how concentrations of multiple nutritional currencies are physiologically constrained by toxins can create a united context to explain how animals reach nutritional balance through selection or avoidance of both nutrients and toxins. For example, understanding the physiological capacity to absorb, metabolize, exploit and resist the bioactivity of phytochemicals could explain why some individuals are more strongly inhibited by toxins than others (Pass et al., 2001; Sorensen and Dearing, 2003; Sorensen et al., 2004; Shipley et al., 2012; Kohl et al., 2014 and 2015). Mechanistic PBMs adopted from biomedicine could help provide the physiological knowledge needed to 
improve management of herbivores. Specifically, PBMs help estimate the individual mechanisms that could, along with the GF and existing demographic models, better connect individual foraging decisions to population demographic consequences.

\section{Physiologically based models}

Several key features of PBMs make them particularly applicable to generating the data needed to predict demographic responses of vertebrate herbivores to phytochemicals. First, PBMs have a strong genetic basis that can explain demographic outcomes. For example, genetic variation in efflux transporters and metabolizing enzymes that influence systemic exposure to drugs predict survival of human patients (Nowell et al., 2005; Ekhart et al., 2009). Similarly, microbial genetic diversity within hosts can influence changes in body mass and survival of humans (Turnbaugh et al., 2006; Celleno et al., 2007; Tucci et al., 2010). Second, the in vivo and in vitro assays developed to estimate physiological responses to drugs and nutrients for personalized medicine provide ecologists with the necessary experimental tools to quantify physiological data to parameterize PBMs (see Supplementary Material S1). Lastly, while the focus of pharmacological PBMs is to predict human responses to drugs, the physiological processes of absorption and metabolism of drugs are transferable to understanding exposure to both toxic and nutritional phytochemicals in wild herbivores.

While there are numerous physiological mechanisms that could link intake of phytochemicals to demographics, we focus on the physiological processes that influence exposure to phytochemicals. We define phytochemical exposure as the concentration-time course of phytochemicals in the gut, blood or tissues that are linked to changes in physiological function and body mass. Phytochemical exposure is influenced by expression of genes, and activities of proteins and microbes that regulate the absorption and distribution (e.g. efflux transporters), as well as metabolism and excretion (e.g. metabolizing enzymes) of ingested phytochemicals (Sorensen et al., 2006; Forbey et al., 2013). For physiological function, we focus on concentration-dependent changes in digestive and metabolic function because phytochemicals alter digestion and cellular metabolism by vertebrates (Spalinger et al., 2010; Au et al., 2013; Kohl et al., 2015) and microbes (Calsamiglia et al., 2007; Patra and Saxena, 2011; Al-Jumaili et al., 2017). For example, diet interacts with the microbiome to change short chain fatty acid absorption that regulates histone acetylation and cellular energy (West and Meng, 1968; Schilderink et al., 2013; den Besten et al., 2013). In addition, many toxic phytochemicals can inhibit digestive enzymes (Kohl et al., 2015) as well as enzymes responsible for cellular energy production (Forbey et al., 2011). This variation in the efficiency of digestion and cellular metabolism may influence the nutritional resources available for animals to grow, survive and reproduce.

There are no examples, to our knowledge, in wild vertebrate systems that predict phytochemical exposure and resultant changes in available nutrients through PBMs. As such, we describe the specific parameter estimates that can be used in PBMs and demonstrate how PBM outputs can be integrated into existing ecological models to predict demographic consequences (Figure 1). The equations we describe here have been developed for toxic phytochemicals. However, we provide initial ideas of how these equations can be used to predict changes in the nutritional balances that translate to demographic consequences. Our mathematical example chooses energy as the nutritional currency using the assumption that the animal may be limited in energy. Focusing on energy allows PBM predictions to directly integrate into existing bioenergetic models that predict demographics (e.g. DEB model, Kooijman and Metz, 1984). However, we acknowledge that to fully understand the underlying nutritional drivers behind the foraging decisions and consequent effects on population dynamics of herbivores, a whole range of nutritional and anti-nutritional constituents and the balance among them must be considered (Simpson and Raubenheimer, 2001 and 2012). Therefore, other nutritional constituents, such as protein, carbohydrates, fats or minerals, can be similarly used as currencies in the models.

\section{Predicting systemic exposure to ingested phytochemicals}

The ability to predict systemic exposure of ingested chemicals has a long history in pharmacology (Teorell, 1937a and 1937b; Bellman et al., 1960; Jacquez et al., 1960). The addition of PBMs to pharmacological models increased the ability to predict drug concentrations and responses among species with distinct genetic, morphological and physiological traits (Boxenbaum, 1982; Dsouza and Boxenbaum, 1988). Likewise, PBMs that predict systemic exposure of phytochemicals in the body could help ecologists predict phytochemical responses within and among species that are known to differ in physiological capacity and dietary specialization (Pass et al., 2001; Sorensen and Dearing, 2003; Sorensen et al., 2004; Shipley et al., 2012).

We use mathematical kinetic models and physiological parameter estimates to predict phytochemical exposure (i.e. concentration of phytochemical over time) in the gastrointestinal tract (hereafter, gut; sub index $G$ in models) and blood (sub index $B$ in models) of an herbivore after a single meal (Figure 2, Table 1). For our models, we let $I(t)$ be the food intake of an herbivore at time $t$. The parameter $p$ is the concentration of toxic phytochemical consumed, and parameter $(1-p)$ is the concentration of nutritional phytochemical consumed. For nutritional phytochemicals, they are further divided into two categories: those that can be absorbed directly across the gut (e.g. glucose and protein) and those that must first be digested or altered by host or microbial enzymes before absorption (e.g. by pancreatic (Whitcomb and Lowe, 2007) and brush border (Pontremoli et al., 2015) enzymes of hosts; cellulase of microbes (Svartström et al., 2017; Comtet-Marre et al., 2018)). We let $(1-r)$ be the proportion of the nutrient that can be absorbed directly and $r$ is the proportion of the same nutrient, which 


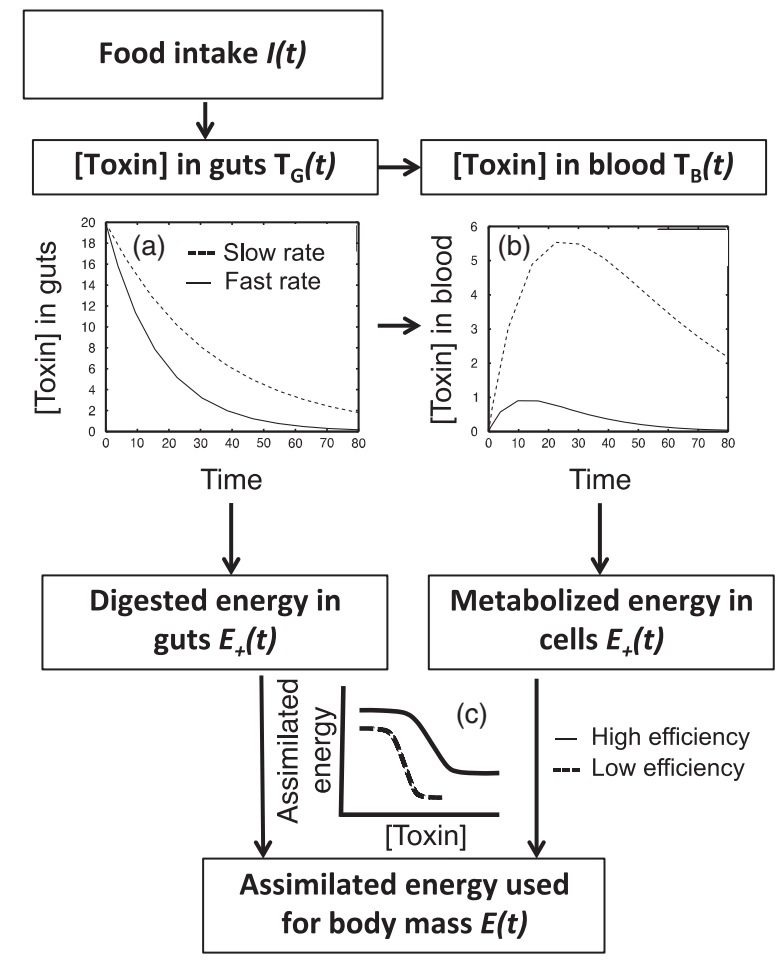

Figure 2 Example of concentrations of toxic phytochemicals ([Toxin] toxin exposure) resulting from food intake in gut compartments (a) and blood (b) predicted from physiologically based models that translate to changes in assimilated energy (c) for a theoretical vertebrate herbivore that has high (solid line) and low (dashed line) efficiency of digestion and metabolism of energy from ingested food (see Table 1 for parameter definitions). Specifically, the solid line represents the scenario for a specialized herbivore with relatively high tolerance to a given toxic phytochemical that has specialized molecular mechanisms that limit absorption $\left(k_{a G}=0.01\right)$ and maximize metabolism in the gut by both herbivore and microbes $\left(k_{m G}=0.05\right)$ and in the liver of the herbivore $\left(k_{m L}=0.1\right)$. The dashed line represents the scenario for a generalized herbivore with relatively low tolerance to the same toxic phytochemical that has generalized molecular mechanisms resulting in relatively higher absorption rates $\left(k_{a G}=0.03\right)$ and slower metabolism in the gut $\left(k_{m G}=\right.$ $0.05)$ and liver $\left(k_{m L}=0.05\right)$. Other parameter values are constant: $G_{0}$ and $B_{0}=20, V=1$ (equations (1) to (4)). Efficiency of digestion (e.g. microbial function) and energy metabolism in the cells (e.g. mitochondrial metabolism) are dependent on [Toxin] and mediate assimilated energy for animals used to determine body mass.

requires digestion or other modification before absorption. To determine exposure to phytochemicals in the gut, we let $T_{G}(t)$ be the amount of toxic phytochemical in the gut at time $t$. We let $k_{a G}$ be the absorption rate of the phytochemical from the gut compartment into the blood and we let $k_{m G}$ be the rate of phytochemical metabolized (for toxins) or digested (for nutrients) by both host and microbial enzymes in the gut before absorption. These rates are dependent on the physio-chemical properties (e.g. tissue/blood partition coefficients, Camp et al., 2015a; Daina et al., 2017) of each ingested phytochemical and the expression and activity of transport and metabolizing proteins by hosts and associated microbiome (Peters and McLeod, 2008; Peters et al., 2016; Wilson and Nicholson, 2017; Cui, 2018; Santos et al., 2018). Rates may also be influenced by interactions with other cooccurring phytochemicals consumed by the herbivores
(Chung et al., 2007; Androutsopoulos et al., 2010; Chen et al., 2010).

For toxic phytochemicals, the variable $T_{G}(t)$ satisfies the following differential equation:

$$
\frac{d T_{G}(t)}{d t}=p l(t)-k_{a G} T_{G}(t) G(t)-k_{m G} T_{G}(t)
$$

For nutritional phytochemicals, $N_{G}(t)$ satisfies the following differential equation:

$$
\frac{d N_{G}(t)}{d t}=(1-p)(1-r) I(t)+(1-p) k_{m G} r l(t)-k_{a G} N_{G}(t)
$$

both with given initial values. For toxins, this equation means the rate of change of toxin in the gut (i.e. phytochemical exposure in the gut, Figure 2) equals the amount of toxin absorbed from the gut compartment into the blood minus the amount of phytochemical metabolized by herbivores and gut microbes before absorption. For nutrients, the rate of change of nutrient in the gut equals the amount of nutrient directly absorbed from the gut compartment into the blood plus the amount of nutrient digested (or liberated) by herbivores and gut microbes before absorption. In other words, host and microbial modification in the gut reduces $T_{G}(t)$ of toxic phytochemicals, whereas host and microbial modification, specifically digestion of larger macronutrients in the gut, increases $N_{G}(t)$ of nutritional phytochemicals in the gut.

To determine systemic exposure to phytochemicals (i.e. concentration over time in blood), we let $T_{B}(t)$ and $N_{B}(t)$ denote the concentration of toxic phytochemical and nutritional phytochemical in the blood, respectively. For toxins, systemic exposure is reduced by first pass metabolism in the liver and distribution of toxin into tissues. We let $k_{m L}$ be the rate of toxin metabolized by drug metabolizing enzymes in the liver of the host and $k_{a b}$ be the absorption rate, or distribution, of the phytochemical from the blood compartment into tissues. We let $V_{B}$ be the total volume of blood estimated from allometric equations (Lindstedt and Schaeffer, 2002).

For toxins, the dynamics of $T_{B}(t)$ can be described by the following differential equation which represents a one compartment model:

$$
V_{B} \frac{d T_{B}(t)}{d t}=k_{m G} T_{G}(t)-V_{B} k_{m L} T_{B}(t)
$$

Existing pharmacological pharmacokinetic models allow for this equation to include multiple compartments where the distribution of toxins from blood into other tissue compartments can be included (Macheras and lliadis, 2006). For nutrients, the dynamics of $N_{B}(t)$ can be described by the following differential equation:

$$
V_{B} \frac{d N_{B}(t)}{d t}=k_{a G} N_{G}(t)-V_{B} k_{a B} N_{B}(t)
$$

with given initial conditions for both equations. The toxin equation means that the rate of change of the total amount of toxin in the blood (i.e. phytochemical exposure in the blood, Figure 2) equals the amount of toxin absorbed from the gut compartment into the blood minus the amount of toxin 
Forbey, Liu, Caughlin, Matocq, Vucetich, Kohl, Dearing and Felton

Table 1 Definition of parameters used in models to predict physiological responses to the intake of phytochemicals by vertebrate herbivores

\begin{tabular}{|c|c|c|}
\hline Symbols & Definition & Units \\
\hline \multicolumn{3}{|l|}{ Variables } \\
\hline$T_{G}(t)$ & The amount of toxic phytochemical in the gut at time $t$ & Mass \\
\hline$N_{G}(t)$ & The amount of nutritional phytochemical in the gut at time $t$ & Mass \\
\hline$T_{B}(t)$ & The concentration of toxic phytochemical in the blood & Mass/volume \\
\hline$N_{B}(t)$ & The concentration of nutritional phytochemical in the blood & Mass/volume \\
\hline$I(t)$ & The food intake of an herbivore at time $t$ & Mass \\
\hline$E(t)$ & The assimilated energy & Energy \\
\hline \multicolumn{3}{|c|}{ Parameters } \\
\hline$p$ & The concentration of toxic phytochemical consumed in food & Mass \\
\hline$r$ & The proportion of the nutrient, which requires digestion or other modification before absorption & \\
\hline$k_{m G}$ & $\begin{array}{l}\text { The rate of phytochemical metabolized (for toxins) or digested (for nutrients) by both host and microbial } \\
\text { enzymes in the gut before absorption }\end{array}$ & 1/time \\
\hline$k_{a G}$ & The absorption rate of the phytochemical from the gut compartment into the blood & $1 /$ time \\
\hline$V_{B}$ & The total volume of blood & Volume \\
\hline$k_{m L}$ & The rate of toxin metabolized by drug metabolizing enzymes in the liver of the host & 1/time \\
\hline$k_{a B}$ & The absorption rate, or uptake, of the phytochemical from the blood compartment into tissues & 1/time \\
\hline$P_{\max }$ & The maximum phytochemical concentration an herbivore can tolerate & Mass/volume \\
\hline$I_{0}$ & The intake of food by an herbivore without toxin & Mass \\
\hline$k_{d G}$ & The digestive efficiency of nutrients in food without toxins in the gut & \\
\hline$k_{e B}$ & The energy (or other nutrient) metabolized from food without toxins & $\begin{array}{l}\text { Energy/mass of food } \\
\text { without toxins }\end{array}$ \\
\hline$d$ & Scaling parameter measuring the impact of toxins on the digestive efficiency & $1 /$ mass \\
\hline$q$ & Scaling parameter measuring the impact of toxins on the energy metabolized from food & Volume/mass \\
\hline$a$ & The energy required to metabolize and eliminate each unit of toxin from the body & Energy/mass toxins \\
\hline$E_{0}$ & Energy allocated to maintain basal metabolic rate & Energy \\
\hline
\end{tabular}

metabolized by the liver or distributed into other compartments. For nutrients, the rate of change of the total amount of nutrient in the blood is the amount of nutrient absorbed from the gut compartment into the blood minus the uptake rate of nutrient from the blood into tissue compartments where it is used for cellular metabolism. If the animal is in a deficit for a particular nutrient, which means that the value of $N_{B}$ (equation (4)) is too low, the equation can be modified to account for the additional amount of nutrient generated endogenously by the liver or other body compartments (e.g. glucose, lipids; Schultz et al., 2015; Yu et al., 2016).

\section{Predicting change in nutritional resources}

Phytochemical exposure in the gut or blood estimated from PBMs can be used to predict changes in the availability of nutritional resources required for herbivores to gain body mass (Figure 3 ). In the simplest scenario, $I(t)$ (food intake) is decided by the following:

$$
I(t)=\geq\left\{\begin{array}{cc}
\frac{P_{\max }-T_{B}(t)}{P_{\max }} I_{0}, & \text { if } T_{B}(t) \leqq P_{\max } \\
0, & \text { if } T_{B}(t)>P_{\max }
\end{array}\right.
$$

where, $P_{\max }$ is the maximum phytochemical concentration an herbivore can tolerate. The term $I_{0}$ the intake of food by an herbivore without toxin or that does not contain nutrients in excess of requirements whose value may be taken as the ratio of the bite size of food and the time used to take this bite. The novel component in our initial PBM is that we allow food intake of an herbivore to be instantaneously influenced by concentration of toxic and nutritional phytochemicals that are in excess of what herbivores can tolerate. Several studies demonstrate upper limits, thresholds or rules of compromise for single or interacting phytochemicals (Sorensen et al., 2005b and 2005a; Felton et al., 2009; Raubenheimer et al., 2009 and 2014; Torregrossa and Dearing, 2009; Rothman et al., 2011; Frye et al., 2013; Solon-Biet et al., 2014; Camp et al., 2015b). However, we recognize that few thresholds are absolute and estimates of $P_{\max }$ must be determined based on specific genetic, physiological, behavioral and environmental conditions (see Supplementary Material S1). Parameters estimated from PBMs could help explain the physiological conditions that influence thresholds and nutritional compromises observed within and among species (see Supplementary Material S2).

We present a simplified example of how the nutritional currency of energy (E) needed for mass gain can be influenced by toxin exposure estimated from PBMs (Figure 2). We let $E_{+}(t)$ denote the energy intake at time $t$. The energy intake from food is decided by how much food is consumed, the concentration of toxin in food, and the toxin-dependent changes in digestive and metabolic function that converts food into assimilated energy. We assume the energy intake at time $t$ is defined as:

$$
E_{+}(t)=\frac{k_{e B}}{1+q T_{B}(t)} \frac{k_{d G}}{1+d T_{G}(t)}(1-p) l(t)
$$

where $k_{d G}$ is the digestive efficiency of nutrients in food without toxins in the gut, which is decreased by higher toxin concentrations in the gut $\left(T_{G}(t)\right.$ ) (Robbins et al., 1991; Kohl 

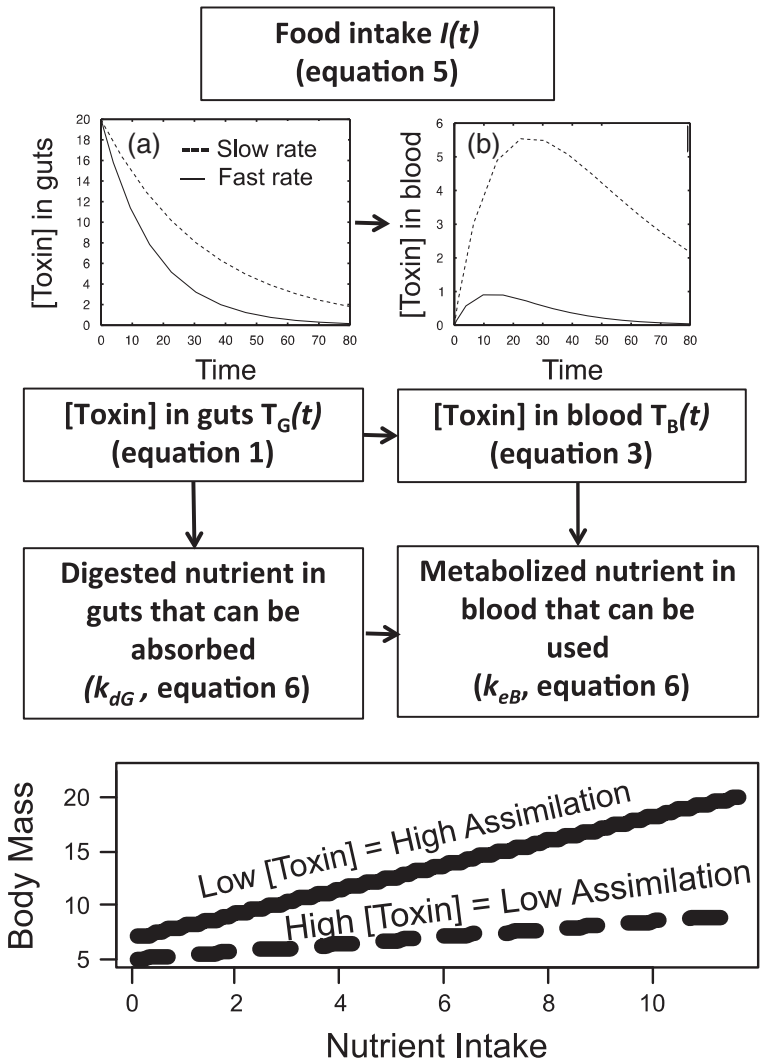

Figure 3 Example of how estimated concentrations of toxic phytochemicals ([Toxin], toxin exposure) resulting from food intake influences body mass through changes in nutrient assimilation (digested and metabolized) in a theoretical vertebrate herbivore predicted by physiologically based models (see Table 1 for parameter definitions).

et al., 2015) with a scaling parameter $d . k_{e B}$ is the energy (or other nutrient) metabolized from food without toxins in the blood, which is decreased by higher toxin concentrations in the blood $\left(T_{B}(t)\right)$ (e.g. Forbey et al., 2011) with a scaling parameter $q$.

The rate of change of total assimilated energy $E(t)$, or net energy assimilated, equals the difference between energy intake $E_{+}(t)$ and the sum of: energy used to eliminate the toxins (before and after absorption), energy lost due to toxindependent reduction in digestive efficiency in the gut (Robbins et al., 1991; Kohl et al., 2015), toxin-dependent reduction in energy metabolism in cells (Forbey et al., 2011), and energy allocated to maintain basal metabolic rate $\left(E_{0}\right)$. Net energy assimilated is shown by the equation:

$$
\frac{d E(t)}{d t}=E_{+}(t)-a V_{B} k_{m L} T_{B}(t)-E_{0}
$$

The second term on the right side of the equation $\left(a V_{B} k_{m L} T_{B}(t)\right)$ is the loss of endogenous energy and $a$ is the energy required to metabolize and eliminate each unit of toxin from the body. Endogenous loss of energy (or other nutrient currencies) could arise from increased metabolic costs above basal metabolism (Bozinovic and Novoa, 1997; Boyle and Dearing, 2003; McLister et al., 2004) or loss of endogenous substrates, such as glucose in the form of glucuronic acid conjugates, required for detoxification
(Guglielmo et al., 1996; Sorensen et al., 2005b; Marsh et al., 2006; Au et al., 2013; Parikh et al., 2017).

\section{Predicting change in body mass}

From the available energy $E(t)$, we can predict relative toxindependent changes in body mass that determine demographic rates. In some cases, we know the energetic costs associated with the intake of toxic plants can result in loss of body mass (Guglielmo et al., 1996; Sorensen et al., 2005b). As such, we predict smaller body mass is associated with lower assimilated energy predicted from PBMs when a given animal is consuming toxic phytochemicals (Figure 3 ). While the initial physiological models we present focus on energy, any nutritional currency that is known to change body mass or other demographic parameters could be modeled with these equations and then integrated into population models.

\section{Predicting population-level responses to phytochemicals}

For physiological predictions, we have relied on human biomedical insights used to predict individual responses to specific doses of phytochemicals (e.g. personalized medicine, Alyass et al., 2015; Aarnoutse et al., 2017). However, the ultimate measure of whether phytochemical exposure and resultant changes in physiological function associated with foraging matter for ecology, evolution and conservation of wildlife is whether variations in these parameters change individual fitness and, ultimately, population growth rates. There is an extensive and sustained effort to model the links among foraging behavior, physiology and demography (e.g. Kooijman and Metz, 1984; Moen et al., 1997; Nisbet et al., 2000; Wikelski and Cooke, 2006). The most salient challenge remaining in this context is to build models that are structured in ways that make an insightful connection between physiology and demography, yet are estimable via statistical analysis of available data. The DEB growth model, or Kooijman-Metz model (Kooijman and Metz, 1984), offers one approach where physiological data from individuals (e.g. body size) is used to describe growth and reproduction parameters that predict population dynamics (Smallegange et al., 2017). The application of DEB models in the field of ecotoxicology demonstrate how energetic responses to exposure to environmental toxins within individuals predict population changes (Kooijman and Metz, 1984; Jager et al., 2014; Desforges et al., 2017). In addition, recent agentbased models (ABMs) demonstrate how energy budgets of individual organisms can be used to predict population-level responses to food availability (Sibly et al., 2013).

Despite these well-established theories and modeling advances, there remains a mechanistic gap between knowledge of the phytochemicals consumed by herbivores and the energetic consequences used in DEB models that lead to changes in demographic rates. One major complication in establishing physiology-dependent links between foraging, energetics and demographics is that nutritional currencies do not act in isolation (Felton et al., 2018). Even when devoid of toxin or excess nutrients, intake and thus nutritional balance and changes in body mass are influenced not only by intake 
rates, but also by synergies among simultaneously ingested foods. For example, dietary protein can interact with toxins to influence body mass (Au et al., 2013) while tannins can reduce digestion and metabolism of protein (DeGabriel et al., 2008) thereby reducing reproductive success (DeGabriel et al., 2009). These types of interactions can be captured through estimates of $P_{\max }$ (maximum phytochemical concentration, equation (5)) or adjusting scaling parameters $d$ and $q$ to account for known changes in the efficiency of digestion and metabolism (equation (6)), respectively, that are explicitly dependent on $P_{\max }$. Estimated exposure to each individual phytochemical consumed from PBMs can be used to predict interactions or identify conditions whereby an animal may experience a systemic excess or deficit of a nutrient to explain foraging behaviors.

While consequences of nutrient deficiencies or excess toxins for an animal is relatively easy to understand, it is less obvious that excess levels of nutrients can cause problems. However, examples from wildlife show that excess amounts of specific amino acids in food items can result in reduced food intake (DeGabriel et al., 2002) or increased demand of thermal energy (Soppela et al., 1992). Furthermore, in ruminant herbivores, overingestion of non-structural carbohydrates causes rumen $\mathrm{pH}$ to decline, potentially causing health issues such as ruminal acidosis (Wobeser and Runge, 1975; Cynthia and Scott, 2005; Butler et al., 2008; Müller et al., 2010). The GF is currently the only way to disentangle the effects of nutrient deficiencies from concurrent surpluses on imbalanced diets (Raubenheimer et al., 2005).

\section{Physiologically based models integrated into the geometric framework for nutrition}

The PBMs we present only estimate toxin-dependent changes in nutrient balance in response to a single phytochemical. Although concentrations of specific phytochemicals are associated with loss of body mass in simplified captive feeding trials (McLean et al., 2007; Shipley et al., 2012), our described PBMs do not capture the complex phytochemical state of an individual herbivore. Much research has shown that it is not enough to use a single nutritional proxy to predict fitness (Simpson and Raubenheimer, 2001; Raubenheimer et al., 2009; Rothman et al., 2011; Solon-Biet et al., 2014; Felton et al., 2016; Simpson et al., 2017). Even when we account for direct affects of toxic phytochemicals on nutrient digestibility, it is the balance among nutrients that is important for predicting fitness (Simpson and Raubenheimer, 2001). The GF provides a framework for using estimated exposure to nutrients in the body derived from PBMs to predict how deficits or excess of nutrient concentrations interact to affect fitness in individuals. The GF takes into consideration that the mixture of many different nutritional currencies (energy and specific macroand micronutrients) interact with each other and with toxic phytochemicals to influence food intake and resultant fitness (Simpson and Raubenheimer, 2001 and 2012). Outcomes of GF experiments include response surfaces that predict fitness relative to the intake of specific absolute intakes and ratios of multiple nutrients and therefore capture multi-dimensional parameters of foraging (Simpson and Raubenheimer, 2012).

The benefit of PBMs is that they have the potential to reduce the residual in these response surfaces and more accurately predict fitness outcomes. We propose that individual physiological parameters such as gut and blood concentrations of interacting phytochemicals are more functionally relevant than absolute intake of nutrients alone. In other words, estimates of phytochemical exposure from PBMs provide a mechanistic explanation for fitness consequences relative to observed intake of multiple nutrients. As a simplified example, take two individual herbivores (1 and 2) that consume the same amount of plant material with a known concentration of a toxic phytochemical that inhibits assimilation of an essential nutrient in a concentration-dependent manner (Figure 4). Subject 1 is a specialized herbivore with physiological mechanisms that limit absorption and maximize metabolism of the toxin resulting in relatively low systemic toxin exposure compared to subject 2 (Figures 2 and 4a). In this scenario, subject 2 is exposed to higher concentrations of the toxin and therefore assimilates a lower concentration of the essential nutrient in the body than subject 1 (Figure 4b). Assuming both subjects have similar requirements for the nutrient, subject 2 must consume higher absolute amounts of the nutrient than subject 1 due to lower nutrient assimilation (Figure 4c). Animals not able to compensate for toxin-dependent deficits in assimilation efficiency of nutrients by increasing intake are predicted to have reduced fitness. Based on the GF, the theoretical response surface that includes both of these subjects would show variation in the absolute intake of this nutrient associated with maximum fitness ( $x$-axis in Figure $4 d$ ). We propose that estimates of the concentration of the nutrient in the body generated from PBMs would reduce variation along this nutritional axis and more precisely correlate with fitness outcomes (Figure 4e) than use of absolute intake alone. This approach could be repeated for any number of nutrients included in the GF using physiological predictions derived from PBMs (Figures 2 and 3). This simplified example demonstrates how estimates of phytochemical exposure offered through PBMs could provide more mechanistically accurate predictions of fitness in individual herbivores within the GF.

\section{Physiologically based models integrated into demographic models}

While including more accurate fitness outcomes from physiological exposure of nutrients into the GF is ideal for predicting population consequences, testing model predictions of fitness in vertebrates is often logistically challenging. Changes in body mass represent a realistic fitness surrogate that can be measured in a wide range of vertebrates and then used to develop and test demographic models that predict population-level outcomes of consuming phytochemicals. Body mass is dependent on mechanisms that increase or decrease physiological exposure to nutrients that can create 
(a)

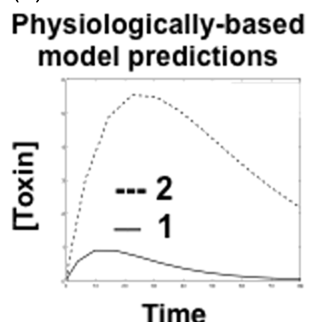

(b)

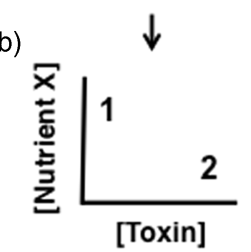

(c)

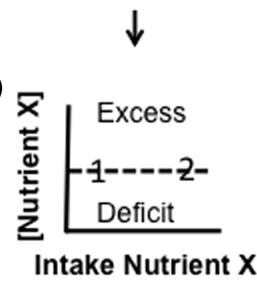

(d)

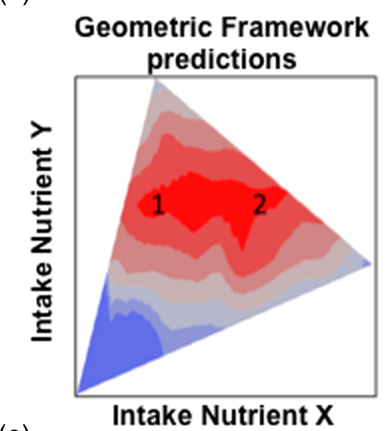

(e)

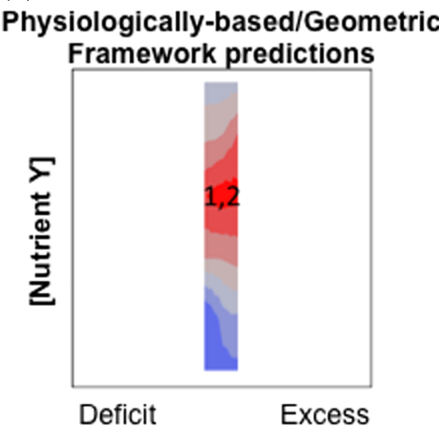

[Nutrient X]

Figure 4 Example showing how predicted concentrations of toxic phytochemicals ([Toxin], toxin exposure, (a)) and toxin-dependent changes in concentrations of an essential nutrient ([Nutrient $X]$, nutrient exposure, (b)) from physiologically based models influence interpretation of response surfaces (red is greater fitness) predicted from the geometric framework (d, e) for a theoretical vertebrate herbivore subject (1) that has physiological mechanisms that limit absorption and maximize metabolism of the toxin more than another theoretical herbivore subject (2). Both herbivores consume the same amount of a toxic phytochemicals and nutrients and the toxin reduces concentrations of Nutrient $X$ in the body in a concentration-dependent manner (b). Subject (2) is exposed to higher concentrations of the toxin and lower concentrations of the essential nutrient in the body (b). To maintain concentrations of Nutrient $X$ (dashed line) required for maintenance (below excess and above deficit), subject (2) must consume higher amounts of the nutrient than subject (1) (c). The theoretical response surface based on absolute intake of Nutrient $X$ generated from the geometric framework would show variation in the absolute intake of Nutrient $X$ associated with maximum fitness (d). In contrast, estimates of the concentration of the nutrient in the body generated from physiologically based models reduce variation along the Nutrient $X$ axis (e) compared to using absolute intake because both subjects are consuming food to reach an optimal body concentration of nutrient $\mathrm{X}$.

nutritional imbalances (Simpson et al., 2003; Simpson and Raubenheimer, 2005; Solon-Biet et al., 2014; Sorensen et al., 2005b and 2008). Quantifying physiology-dependent nutrient concentrations in the body and resultant changes in body mass of individuals within a population will get ecologists closer to accurately predicting demographic consequences for vertebrates. Nutrient concentrations in the body can be estimated from PBMs (Figures 2 and 3) parameterized with physiological data from in vitro and in vivo assays (described in Supplementary Material S1) and body mass can be measured directly from whole animals or indirectly from fecal pellet size in some species (Coe and Carr, 1983; Smith et al., 1995; Reilly, 2002; Morden et al., 2011). Numerous studies have demonstrated that body size predicts the demography
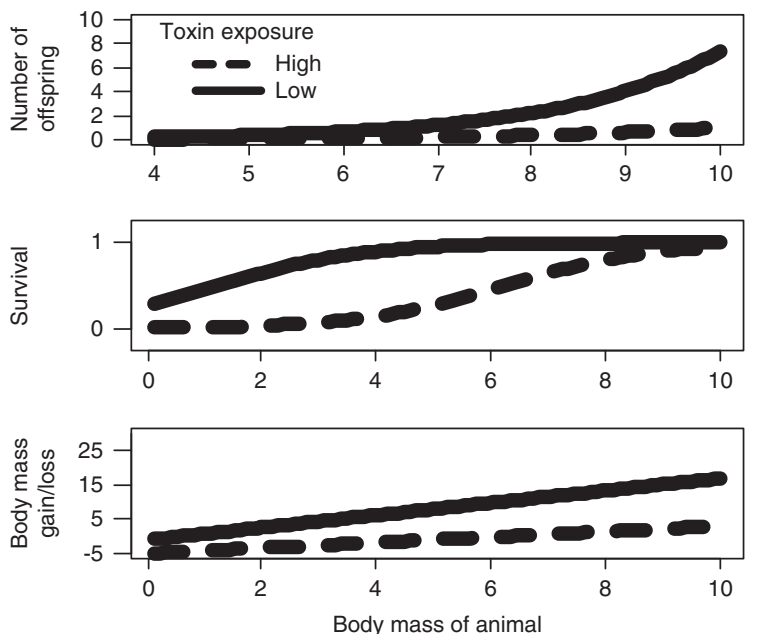

Figure 5 Example of demographic changes based on body mass relative toxin exposure of individual animals predicted from integral projection models. Toxin exposure and body mass are predicted from physiologically based models (Figures 2 and 3) or measured directly from individuals. Body mass is one of several surrogates of fitness that could be used.

of long-lived animals, meaning that larger individuals tend to have better growth, survival and reproduction than smaller individuals (Rees et al., 2014; Barneche et al., 2018). Because toxin exposure can influence body size through changes in available energy both in real organisms (Sorensen et al., $2005 \mathrm{~b}$ and 2005c) and in the above physiological models, we propose that size-structured population models (sensu Rees et al., 2014) can translate toxin-dependent changes in assimilated nutrients and body mass in individual animals to changes in population growth rates.

Integral projection models (IPMs) are an example of sizestructured population models that are widely used to quantify evolutionary fitness, forecast impacts of wildlife management and understand why population dynamics vary between geographically separated populations (Metcalf et al., 2003; Coulson et al., 2011; Smallegange et al., 2017). Smallegange et al. (2017) demonstrated that DEB theory can be incorporated into IPMs and that predictions from the resultant DEB-IPM model closely matched empirical data on population growth rate. However, incorporating the physiological details of herbivory in IPMs remains a major research gap. To bridge this gap, we propose developing IPMs that predict demographic rates as a function of both body mass and phytochemical exposure (Figure 5). By including phytochemical exposure along with body mass, we can better account for the potentially interacting consequences of phytochemicals on energy balance as well as any other nutritional currency that influences demographic parameters of animals (e.g. fat or protein composition; Parker et al., 2009). Specifically, IPMs can be fitted with empirically derived physiological parameters to predict body mass or other fitness parameters (e.g. survival or number of offspring). The analytical tractability of IPMs leads to a suite of demographic metrics, including long- and short-term population growth rate, sensitivity of population growth rate to environmental conditions, and stable size distribution, that 
can be easily compared across species and study sites (Rees et al., 2014). The cost of IPMS is that they may be limited in the level of complexity they can handle.

Agent-based models provide an additional modeling framework that can scale-up individual-level variation to population dynamics. Moreover, ABMs can incorporate complex data such as variable genotypes, physiological traits and environmental conditions (Golestani et al., 2012; Sibly et al., 2013; Khater et al., 2016). The ABMs represent individuals within a virtual environment that, based on their individual traits, exhibit differences in growth, survival and reproduction. The ABMs allow researchers to manipulate virtual genotypes (host and microbiome) or physiological functions that would not be feasible in the field (Torrens, 2010; Caughlin et al., 2014 and 2015; Ruktanonchai et al., 2016; Pauli et al., 2017). Virtual individuals can be assigned genome- and phytochemical-dependent physiological responses that are based on empirical data established from in vitro and in vivo experiments (see Supplementary Material S1). When simulated across multiple generations, even subtle differences in individual traits (genomes) and interactions with the environment, such as energetic responses to interacting concentrations of toxins and nutrients predicted from PBMs, can result in emergent patterns of population persistence and trait composition (Grimm et al., 2005). A potential tradeoff of more complex ABMs relative to analytically tractable models (e.g. IPMs) is a lack of generalizability across study systems (Morris and Doak, 2002).

Integrating complex physiological and demographic data into any demographic model presents a challenge because data often comes from disparate sources. Many wildlife monitoring programs offer extensive data on population time series, but rarely collect information on phytochemicals in the diets or physiological data for these populations. Instead, physiological data are most often limited to experimental trials on whole individuals or derived from in vitro assays (see Supplementary Material S1). Physiological data can also be derived from new databases (Daina et al., 2017) that predict the physiological activity of a vast array of metabolites from plants and the excreta of animals based on the structure of the metabolite (Servello and Schneider, 2000; Sauvé and Côté, 2006; Van Duynhoven et al., 2011; Tay-Sontheimer et al., 2014; Parikh et al., 2017). As such, a gap remains between observational data from populations and physiological data from individuals.

Hierarchical Bayesian methods present a way to integrate disparate data sources to model population dynamics, while accounting for imperfect detection (Zipkin and Saunders, 2018). For example, Bayesian models could integrate variation in individual responses to phytochemicals predicted from PBMs (Figures 2 and 3) or predicted from known metabolite structures (Daina et al., 2017), predicted fitness metrics estimated from response surfaces generated from the GF (Figure 4), experimental data from animals in captivity (e.g. body size) or obtained from captured animals in the field, as well as long-term data on population density and abundance of herbivore populations. Hierarchical Bayesian models can be applied to fit both IPMs and ABMs (Caughlin et al., 2015; Elderd and Miller, 2016). Once the joint models (i.e. PBMs within the GF coupled with IPMs or ABMs) are fit to data, sensitivity analysis (Saltelli et al., 2006) presents a way to evaluate the demographic importance of physiological variation. This analysis would enable researchers to quantify how variability in the input of phytochemical exposure (from PBMs), available energy, body mass and fitness metrics translates into output for demographic models (population growth rate). The sensitivity analysis can directly quantify which physiology-dependent parameters best explain population growth rates.

\section{Test and revise models}

While testing physiology-dependent predictions of population dynamics in long-lived species is logistically challenging, we identify a few options for testing and improving initial models.

\section{In vitro manipulation to test physiologically based models} A variety of modifications to in vitro assays can be used to parameterize PBMs (see Supplementary Material S1) and test predictions of those models in specific study organisms (see Supplementary Material S2). Both host enzymes and microbial communities can be exposed in vitro to different combinations of phytochemicals that vary in concentration and composition. For example, Kriszan et al. (2018) quantified changes in efficiency of digestion (fermentation) by testing rumen liquid from free-ranging moose (a browsing species) and dairy cows (a grazing species) on a combination of spring and summer foods commonly eaten by moose in Northern Sweden. The naturally growing plants differed in their nutrient and toxin concentrations. The assay showed that fermentation efficiency is host-specific and related to the composition of the rumen microbial community. Moreover, the pattern was in agreement with the evolutionary adaptations related to feeding habitats and morphophysiological differences between browsers and grazers. Results such as these can be used to identify which phytochemical combinations, microbes and host enzyme activity minimize or maximize exposure to phytochemicals (fast rates of metabolism by microbes) and maximize or minimize physiological function (Figure 1).

\section{In vivo manipulation to test demographic models}

Model predictions can also be tested by in vivo manipulation of the molecular mechanisms regulating phytochemical exposure. Host and/or microbiome enzyme activity can be manipulated through drug-drug interaction assays. A number of phytochemicals naturally consumed by herbivores are known to inhibit transporters and metabolizing enzymes in humans and cause altered systemic exposure to medication (Chung et al., 2007; Androutsopoulos et al., 2010; Chen et al., 2010). For example, phytochemical exposure and demographic responses of populations can be assessed by varying phytochemical concentrations of food given to animals with and without co-administration of inducers (e.g. 
kaempferol, Chung et al., 2007) or inhibitors (e.g. flavonoids, Androutsopoulos et al., 2010) of transporters and metabolizing enzymes. In addition, tolerance to phytochemicals can be altered by pairing variation in dietary phytochemicals with manipulation of microbial communities of the gut (Kohl et al., 2014 and 2016b). The gut microbiome can be manipulated by providing herbivores with food of varying phytochemistry that is mixed with feces or rumen fluid collected from other herbivores with specific physiological mechanisms of tolerance to specific phytochemicals (Jones and Megarrity, 1986; Pratchett et al., 1991; Kohl et al., 2016b; Griffith et al., 2017).

We suggest that coupling the manipulation of phytochemicals with the manipulation of host and microboime function would allow researchers to test model-predicted changes in a number of physiological and demographic parameters. Researchers could observe changes in intake of food of known phytochemistry through direct observations (McShea and Schwede, 1993; Parker et al., 1996; Felton et al., 2009; Johnson et al., 2013) or animal-borne video (Hays, 2015; Garnick et al., 2018). Fecal collections can be used to monitor changes in microbial communities from metagenomic studies and phytochemical exposure in the gut from metabolomic studies. Phytochemical exposure and nutritional indices could be further assessed through concentrations of metabolites in excreta (Servello and Schneider, 2000; Sauvé and Côté, 2006; Van Duynhoven et al., 2011; Tay-Sontheimer et al., 2014; Parikh et al., 2017) and taking direct or indirect measures of changes in body mass. Furthermore, researchers could partner with federal and state wildlife agencies to monitor relationships among physiological function and demographics in free-ranging wild and domestic vertebrate herbivores. State and federal agencies often collect long-term demographic data for game species and routinely monitor body mass, survival and reproductive success of individuals (Bishop et al., 2009; De Jager and Pastor, 2009; Revermann et al., 2012; Zhao et al., 2013; Moss et al., 2014; Coates et al., 2015; DeAngelis et al., 2015; DeMay et al., 2017; Fauchald et al., 2017). These demographic parameters could be coupled with the collection of excreta from animals they handle or track to quantify biomarkers of phytochemical exposure and consequences. For example, the moose (Alces alces) population in Sweden has been monitored in terms of relative density (number of individuals shot) since the mid-1900s. Since then, data on reproductive output (e.g. number of calves/adult female) and condition (carcass weights) of moose populations have been added to the official national database. There are also available data on the population trends of other species of herbivorous game in Sweden, such as roe deer (Capreolus capreolus), fallow deer (Dama dama), the European hare (Lepus timidus) and beaver (Castor fiber). This type of monitoring effort should begin to include collection of excreta from individuals that are handled or are collected from the habitat to quantify phytochemical exposure and physiological responses to those phytochemicals. In addition, researchers are encouraged to link physiological and demographic responses to the genetic expression and activity of host and microbial enzymes responsible for absorption and metabolism of ingested phytochemicals and digestive function (see Supplementary Material S1). While collection of tissues may be problematic in some species, this effort could be aided by collaborations with hunters who can offer access to tissues of game species for coupled genomic and physiological analysis.

\section{Conclusions}

Two key advances are needed to increase our capacity to predict variable demographic outcomes in vertebrate herbivores from complex diets. The first is to identify mechanistic responses to diets that are common across individuals in populations. For example, any animal that consumes and absorbs toxic alkaloids from plants has a high degree of probability for toxicosis (Cheeke, 1989; Panter et al., 1999). The second is to identify mechanisms that explain why individuals within populations differ in their molecular expression, physiological processing of phytochemicals and physiological responses to phytochemical exposure. For example, why one individual has a higher intake of a given nutrient, faster rate of detoxification for a given toxin, or lower sensitivity to cellular toxicity than another individual, to such an extent that it results in differences in ecological or evolutionary dietary specialization (Shipley et al., 2009). The PBMs described here can help increase our capacity to make initial physiological predictions about variable demographic outcomes associated with the degree of dietary specialization.

The immediate challenge for mechanistic models of ecology is to estimate physiological parameters among individuals, populations and species that differ in foraging strategies. Estimates of many physiological parameters can be independently assessed using a number of in vitro and in vivo studies (see examples in Supplementary Material S1). We stress that environmental conditions must be considered in both experimental studies, field observations, and in model parameterization and outputs. Ambient temperature can change nutritional demands of herbivores (e.g. metabolic costs, Hillebrand et al., 2009; Smith-Ramesh et al., 2017; Hristov et al., 2018) and the toxicity of ingested phytochemicals (Dearing, 2013; Connors et al., 2017; Beale et al., 2018). As such, estimating biologically relevant physiological parameters requires knowledge of phytochemical intake within an environmental context, which is always challenging in wild herbivores. Inspiration can be drawn from primate (Felton et al., 2009; Johnson et al., 2013) and ungulate (McShea and Schwede, 1993; Parker et al., 1996) research where the ability to habituate wild individuals to the presence of researchers provides the opportunity to determine detailed dietary intake from free-ranging animals. In addition, there are emerging opportunities for researchers to quantify intake of food through observations of animalborne video (Hays, 2015; Garnick et al., 2018) that could be coupled with remote sensors that detect forage species and 
phytochemical concentrations (Stolter et al., 2006; Yule et al., 2015; Lim et al., 2017) as well as environmental conditions (Faye et al., 2016; Cristóbal et al., 2018) at the same spatial and temporal scales. The next challenge is to then develop mechanistic models that can accommodate known concentrations of phytochemicals in body compartments (PBMs), and resulting fitness consequences (GF), as well as genetic and metagenomic data (e.g. Zhao et al., 2013; Alyass et al., 2015; Simpson et al., 2017) and environmental conditions to validate how individuals and populations will respond to ingested phytochemicals under different climate scenarios.

There are no studies to our knowledge, outside of pharmacogenomic work in biomedical model organisms (Peters and McLeod, 2008; Santos et al., 2018), that demonstrate how modeling phytochemical exposure and physiological function can predict individual responses to phytochemicals and help manage population dynamics. The described PBMs could help fill that gap. The coupling of a PBM, the GF and demographic models, along with advanced technology that allow us to better estimate behavioral, physiological and environmental parameters will increase our ability to link intake of phytochemicals by herbivores to demographic consequences. The genomic, metabolomic and modeling advances made in biomedicine have increased the predictive power and management tools needed to increase the health of humans. Ecologists should draw on these tools along with investment by state and federal agencies to monitor demographics of wild herbivores and the environment to better understand and manage the physiological mechanisms driving existing or desired demographic trends.

\section{Acknowledgments}

The authors thank Isabelle Cassar-Malek and René Baumont for their invitation to the 10th edition of the International Symposium on the Nutrition of Herbivores (ISNH) and providing a platform for synthesizing and sharing ideas within this manuscript. The authors thank D. Raubenheimer and S. Simpson for sharing their recent advances associated with the geometric framework of nutrition and two anonymous reviewers for valuable recommendations to improve the manuscript. J.S.F. was funded by the National Science Foundation (DEB-1146194, OIA-1826801). T.T.C. was funded by NSF SBE-1415297. M.D.M. was supported by NSF-IOS 1457209. M.D.D. was funded by NSF-IOS 1256383. A.M.F. was funded by the Swedish Environmental Protection Agency (13/274), the Södra Research Fund, and the Swedish Council for Sustainable Development (2016-01140-3). J.S.F. and A.M.F. equally conceived the manuscript. R.L. conceived the physiology-base models and outputs and T.T.C. conceived the demographic model outputs. J.S.F., R.L., T.C.C., M.D.M., J.A.V., K.D.K., M.D.D. and A.M.F. equally contributed to the integrating ideas across biological scales and writing.

\section{Declaration of interest}

All authors declare no conflicts of interest and no competing interests.

\section{Ethics statement}

Not applicable.

Software and data repository resources

None of the data were deposited in an official repository.

\section{Supplementary materials}

To view supplementary material for this article, please visit https://doi.org/10.1017/S1751731118002264

\section{References}

Aarnoutse R, de Vos-Geelen J, Penders J, Boerma EG, Warmerdam F, Goorts B, Damink SO, Soons Z, Rensen SSM and Smidt ML 2017. Study protocol on the role of intestinal microbiota in colorectal cancer treatment: a pathway to personalized medicine 2.0. International Journal of Colorectal Disease 32, 1077-1084. Al-Jumaili WS, Goh YM, Jafari S, Rajion MA, Jahromi MF and Ebrahimi M 2017. An in vitro study on the ability of tannic acid to inhibit methanogenesis and biohydrogenation of C18 rufa in the rumen of goats. Annals of Animal Science 17, 491-502. Alyass A, Turcotte M and Meyre D 2015. From big data analysis to personalized medicine for all: challenges and opportunities. BMC Medical Genomics 8, 33.

Androutsopoulos VP, Papakyriakou A, Vourloumis D, Tsatsakis AM and Spandidos DA 2010. Dietary flavonoids in cancer therapy and prevention: substrates and inhibitors of cytochrome P450 CYP1 enzymes. Pharmacology \& Therapeutics 126, 9-20.

Au J, Marsh KJ, Wallis IR and Foley WJ 2013. Whole-body protein turnover reveals the cost of detoxification of secondary metabolites in a vertebrate browser. Journal of Comparative Physiology B 183, 993-1003.

Barneche DR, Robertson DR, White CR and Marshall DJ 2018. Fish reproductiveenergy output increases disproportionately with body size. Science 360, 642-645. Beale PK, Marsh KJ, Foley WJ and Moore BD 2018. A hot lunch for herbivores: physiological effects of elevated temperatures on mammalian feeding ecology. Biological Reviews 93, 674-692.

Bellman R, Jacquez JA and Kalaba R 1960. Some mathematical aspects of chemotherapy: I. One-organ models. The Bulletin of Mathematical. Biophysics 22, 181-198.

Belovsky GE 1978. Diet optimization in a generalist herbivore: the moose. Theoretical Population Biology 14, 105-134.

Bishop CJ, White GC, Freddy DJ, Watkins BE and Stephenson TR 2009. Effect of enhanced nutrition on mule deer population rate of change. Wildlife Monographs 172, 1-28.

Boxenbaum H 1982. Interspecies scaling, allometry, physiological time, and the ground plan. Journal of Pharmacokinetics and Biopharmaceutics 10, 201-225.

Boyle R and Dearing MD 2003. Ingestion of juniper foliage reduces metabolic rates in woodrat (Neotoma) herbivores. Zoology 106, 151-158.

Bozinovic F and Novoa FF 1997. Metabolic costs of rodents feeding on plant chemical defenses: a comparison between an herbivore and an omnivore. Comparative Biochemistry and Physiology Part A: Physiology 117, 511-514.

Bray MS, Loos RJ, McCaffery JM, Ling C, Franks PW, Weinstock GM, Snyder MP, Vassy JL, Agurs-Collins T and Group CW 2016. NIH working group report-using genomic information to guide weight management: from universal to precision treatment. Obesity 24, 14-22.

Brittas R 1988. Nutrition and reproduction of the willow grouse Lagopus lagopus in Central Sweden. Ornis Scandinavica 19, 49-57.

Butler EA, Jensen WF, Johnson RE and Scott JM 2008. Grain overload and secondary effects as potential mortality factors of moose in North Dakota. Alces: A Journal Devoted to the Biology and Management of Moose 44, 73-79.

Calsamiglia S, Busquet M, Cardozo PW, Castillejos L and Ferret A 2007. Essential oils as modifiers of rumen microbial fermentation. Journal of Dairy Science 90, 2580-2595.

Camp D, Garavelas A and Campitelli M 2015a. Analysis of physicochemical properties for drugs of natural origin. Journal of Natural Products 78, 1370-1382. Camp MJ, Shipley LA, Johnson TR, Forbey JS, Rachlow JL and Crowell MM 2015b. Modeling trade-offs between plant fiber and toxins: a framework for quantifying risks perceived by foraging herbivores. Ecology 96, 3292-3302. 
Campbell M, Oakeson KF, Yandell M, Halpert JR and Dearing D 2016. The draft genome sequence and annotation of the desert woodrat Neotoma lepida. Genomics Data 9, 58-59.

Caughlin TT, Ferguson JM, Lichstein JW, Bunyavejchewin S and Levey DJ 2014. The importance of long-distance seed dispersal for the demography and distribution of a canopy tree species. Ecology 95, 952-962.

Caughlin TT, Ferguson JM, Lichstein JW, Zuidema PA, Bunyavejchewin S and Levey DJ 2015. Loss of animal seed dispersal increases extinction risk in a tropical tree species due to pervasive negative density dependence across life stages. Proceedings of the Royal Society B 282, 20142095.

Celleno L, Tolaini MV, D'Amore A, Perricone NV and Preuss HG 2007. A dietary supplement containing standardized Phaseolus vulgaris extract influences body composition of overweight men and women. International Journal of Medical Sciences 4, 45-52.

Charnov EL 1976. Optimal foraging, the marginal value theorem. Theoretical Population Biology 9, 129-136.

Cheeke PR 1989. Pyrrolizidine alkaloid toxicity and metabolism in laboratory animals and livestock. CRC Press, Boca Raton, FL, USA.

Chen C, Zhou J and Ji C 2010. Quercetin: a potential drug to reverse multidrug resistance. Life Sciences 87, 333-338.

Chung SY, Jang DS, Han A-R, Jang JO, Kwon Y, Seo E-K and Lee HJ 2007. Modulation of P-glycoprotein-mediated resistance by kaempferol derivatives isolated from Zingiber zerumbet. Phytotherapy Research 21, 565-569.

Coates PS, Ricca MA, Prochazka BG, Doherty KE, Brooks ML and Casazza ML 2015. Long-term effects of wildfire on greater sage-grouse-Integrating population and ecosystem concepts for management in the Great Basin. U.S. Geological Survey Open-File Report, Reston, VA, USA.

Coe MJ and Carr RD 1983. The relationship between large ungulate body weight and faecal pellet weight. African Journal of Ecology 21, 165-174.

Comtet-Marre S, Chaucheyras-Durand F, Bouzid O, Mosoni P, Bayat AR, Peyret P and Forano E 2018. FibroChip, a functional DNA microarray to monitor cellulolytic and hemicellulolytic activities of rumen microbiota. Frontiers in Microbiology 9, 215. Connors PK, Malenke JR and Dearing MD 2017. Ambient temperature-mediated changes in hepatic gene expression of a mammalian herbivore (Neotoma lepida). Molecular Ecology 26, 4322-4338.

Coulson T, MacNulty DR, Stahler DR, vonHoldt B, Wayne RK and Smith DW 2011. Modeling effects of environmental change on wolf population dynamics, trait evolution, and life history. Science 334, 1275-1278.

Cristóbal J, Jiménez-Muñoz JC, Prakash A, Mattar C, Skoković D and Sobrino JA 2018. An improved single-channel method to retrieve land surface temperature from the Landsat-8 thermal band. Remote Sensing 10, 431.

Cui JY 2018. Understanding the GUT microbiome-liver axis in xenobiotic biotransformation. Drug Metabolism and Pharmacokinetics 33, S10.

Cynthia MK and Scott L 2005. The Merck veterinary manual. Merck \& Co, Whitehouse Station, NJ, USA.

Daina A, Michielin 0 and Zoete V 2017. SwissADME: a free web tool to evaluate pharmacokinetics, drug-likeness and medicinal chemistry friendliness of small molecules. Scientific Reports 7, 42717.

DeAngelis DL, Bryant JP, Liu R, Gourely SA, Krebs CJ and Reichardt PB 2015. A plant toxin mediated mechanism for the lag in snowshoe hare population recovery following cyclic declines. Oikos 124, 796-805.

Dearing DM, Mangione AM and Karasov WH 2002. Ingestion of plant secondary compounds causes diuresis in desert herbivores. Oecologia 130, 576-584.

Dearing MD 2013. Temperature-dependent toxicity in mammals with implications for herbivores: a review. Journal of Comparative Physiology B 183, 43-50.

DeGabriel J, Foley W and Wallis I 2002. The effect of excesses and deficiencies in amino acids on the feeding behaviour of the common brushtail possum (Trichosurus vulpecula). Journal of Comparative Physiology B 172, 607-617.

DeGabriel JL, Moore BD, Felton AM, Ganzhorn JU, Stolter C, Wallis IR, Johnson CN and Foley WJ 2014. Translating nutritional ecology from the laboratory to the field: milestones in linking plant chemistry to population regulation in mammalian browsers. Oikos 123, 298-308.

DeGabriel JL, Moore BD, Foley WJ and Johnson CN 2009. The effects of plant defensive chemistry on nutrient availability predict reproductive success in a mammal. Ecology 90, 711-719.

DeGabriel JL, Wallis IR, Moore BD and Foley WJ 2008. A simple, integrative assay to quantify nutritional quality of browses for herbivores. Oecologia 156, 107-116.
De Jager NR and Pastor J 2009. Declines in moose population density at Isle Royle National Park, MI, USA and accompanied changes in landscape patterns. Landscape Ecology 24, 1389-1403.

den Besten G, van Eunen K, Groen AK, Venema K, Reijngoud D-J and Bakker BM 2013. The role of short-chain fatty acids in the interplay between diet, gut microbiota, and host energy metabolism. Journal of Lipid Research 54, 23252340.

DeMay SM, Becker PA, Rachlow JL and Waits LP 2017. Genetic monitoring of an endangered species recovery: demographic and genetic trends for reintroduced pygmy rabbits (Brachylagus idahoensis). Journal of Mammalogy 98, 350-364.

Desforges J-PW, Sonne C and Dietz R 2017. Using energy budgets to combine ecology and toxicology in a mammalian sentinel species. Scientific Reports 7 , 46267.

Dsouza R and Boxenbaum H 1988. Physiological pharmacokinetic models some aspects of theory, practice and potential. Toxicology and Industrial Health 4, 151-171.

Ekhart C, Rodenhuis S, Smits PH, Beijnen JH and Huitema AD 2009. An overview of the relations between polymorphisms in drug metabolising enzymes and drug transporters and survival after cancer drug treatment. Cancer Treatment Reviews 35, 18-31.

Elderd BD and Miller TEX 2016. Quantifying demographic uncertainty: Bayesian methods for integral projection models. Ecological Monographs 86, 125-144.

Emlen JM 1966. The role of time and energy in food preference. The American Naturalist 100, 611-617.

Esch EW, Bahinski A and Huh D 2015. Organs-on-chips at the frontiers of drug discovery. Nature Reviews Drug Discovery 14, 248-260.

Fauchald P, Park T, Tømmervik H, Myneni R and Hausner VH 2017. Arctic greening from warming promotes declines in caribou populations. Science Advances 3, e1601365.

Faye E, Rebaudo F, Yánez-Cajo D, Cauvy-Fraunié S and Dangles 0 2016. A toolbox for studying thermal heterogeneity across spatial scales: from unmanned aerial vehicle imagery to landscape metrics. Methods in Ecology and Evolution 7, 437-446.

Felton AM, Felton A, Raubenheimer D, Simpson SJ, Foley WJ, Wood JT, Wallis IR and Lindenmayer DB 2009. Protein content of diets dictates the daily energy intake of a free-ranging primate. Behavioral Ecology 20, 685-690.

Felton AM, Felton A, Raubenheimer D, Simpson SJ, Krizsan SJ, Hedwall P-0 and Stolter $C 2016$. The nutritional balancing act of a large herbivore: an experiment with captive moose (Alces alces L). PLoS One 11, e0150870.

Felton AM, Wam HK, Stolter C, Mathisen KM and Wallgren M 2018. The complexity of interacting nutritional drivers behind food selection, a review of northern cervids. Ecosphere 9, e02230.

Feng Z, Liu R, DeAngelis DL, Bryant JP, Kielland K, Chapin FS III and Swihart RK 2009. Plant toxicity, adaptive herbivory, and plant community dynamics. Ecosystems $12,534-547$.

Forbey JS, Dearing MD, Gross EM, Orians CM, Sotka EE and Foley WJ 2013. A pharm-ecological perspective of terrestrial and aquatic plant-herbivore interactions. Journal of Chemical Ecology 39, 465-480.

Forbey JS, Pu X, Xu D, Kielland K and Bryant J 2011. Inhibition of snowshoe hare succinate dehydrogenase activity as a mechanism of deterrence for papyriferic acid in birch. Journal of Chemical Ecology 37, 1285-1293.

Frye GG, Connelly JW, Musil DD and Forbey JS 2013. Phytochemistry predicts habitat selection by an avian herbivore at multiple spatial scales. Ecology 94 308-314.

Garnick S, Barboza PS and Walker JW 2018. Assessment of animal-based methods used for estimating and monitoring rangeland herbivore diet composition. Rangeland Ecology \& Management 71, 449-457.

Ge R-L, Cai Q, Shen Y-Y, San A, Ma L, Zhang Y, Yi X, Chen Y, Yang L and Huang Y 2013. Draft genome sequence of the Tibetan antelope. Nature Communications 4, 1858.

Golestani A, Gras R and Cristescu M 2012. Speciation with gene flow in a heterogeneous virtual world: can physical obstacles accelerate speciation? Proceedings of the Royal Society of London B: Biological Sciences 279, 3055-3064.

Gordon D, Huddleston J, Chaisson MJ, Hill CM, Kronenberg ZN, Munson KM, Malig M, Raja A, Fiddes I and Hillier LW 2016. Long-read sequence assembly of the gorilla genome. Science 352 , aae0344.

Griffith C Ribeiro GO Jr, Oba M, McAllister TA and Beauchemin KA 2017. Potential for improving fiber digestion in the rumen of cattle (Bos taurus) 
through microbial inoculation from bison (Bison bison): in situ fiber degradation. Journal of Animal Science 95, 2156-2167.

Grimm V, Revilla E, Berger U, Jeltsch F, Mooij WM, Railsback SF, Thulke H-H Weiner J, Wiegand T and DeAngelis DL 2005. Pattern-oriented modeling of agent-based complex systems: lessons from ecology. Science 310, 987-991.

Guglielmo CG, Karasov WH and Jakubas WJ 1996. Nutritional costs of a plant secondary metabolite explain selective foraging by ruffed grouse. Ecology 77 , 1103-1115.

Gurley BJ, Markowitz JS, Williams DK and Barone GW 2017. Practical considerations when designing and conducting clinical pharmacokinetic herb-drug interaction studies. International Journal of Pharmacokinetics 2, 57-69.

Hays GC 2015. New insights: animal-borne cameras and accelerometers reveal the secret lives of cryptic species. Journal of Animal Ecology 84, 587-589.

Hewson-Hughes AK, Hewson-Hughes VL, Colyer A, Miller AT, McGrane SJ, Hall SR, Butterwick RF, Simpson SJ and Raubenheimer D 2012. Geometric analysis of macronutrient selection in breeds of the domestic dog, Canis lupus familiaris. Behavioral Ecology 24, 293-304.

Hewson-Hughes AK, Hewson-Hughes VL, Miller AT, Hall SR, Simpson SJ and Raubenheimer D 2011. Geometric analysis of macronutrient selection in the adult domestic cat, Felis catus. Journal of Experimental Biology 214, 1039-1051.

Hillebrand H, Borer ET, Bracken MES, Cardinale BJ, Cebrian J, Cleland EE, Elser JJ, Gruner DS, Harpole WS, Ngai JT, Sandin S, Seabloom EW, Shurin JB, Smith JE and Smith MD 2009. Herbivore metabolism and stoichiometry each constrain herbivory at different organizational scales across ecosystems. Ecology Letters $12,516-527$.

Hristov AN, Degaetano AT, Rotz CA, Hoberg E, Skinner RH, Felix T, Li $H_{\text {, }}$ Patterson PH, Roth G, Hall M, Ott TL, Baumgard LH, Staniar W, Hulet RM, Dell CJ, Brito AF and Hollinger DY 2018. Climate change effects on livestock in the Northeast US and strategies for adaptation. Climatic Change 146, 33-45.

Jacquez JA, Bellman R and Kalaba R 1960. Some mathematical aspects of chemotherapy-II: the distribution of a drug in the body. The Bulletin of Mathematical Biophysics 22, 309-322.

Jager T, Barsi A, Hamda NT, Martin BT, Zimmer El and Ducrot V 2014. Dynamic energy budgets in population ecotoxicology: applications and outlook. Ecological Modelling 280, 140-147.

Johnson CA, Raubenheimer D, Rothman JM, Clarke D and Swedell L 2013. 30 Days in the life: daily nutrient balancing in a wild chacma baboon. PLoS ONE 8, e70383. Jones RJ and Megarrity RG 1986. Successful transfer of DHP-degrading bacteria from Hawaiian goats to Australian ruminants to overcome the toxicity of Leucaena. Australian Veterinary Journal 63, 259-262.

Khater M, Murariu D and Gras R 2016. Predation risk tradeoffs in prey: effects on energy and behaviour. Theoretical Ecology 9, 251-268.

Kirmani SN, Banks PB and McArthur C 2010. Integrating the costs of plant toxins and predation risk in foraging decisions of a mammalian herbivore. Oecologia 164, 349-356.

Kohl KD, Connelly JW, Dearing MD and Forbey JS 2016a. Microbial detoxification in the gut of a specialist avian herbivore, the Greater Sage-Grouse. FEMS Microbiology Letters 363, fnw144.

Kohl KD, Pitman E, Connelly JW, Dearing MD and Forbey JS 2015. Monoterpenes as inhibitors of digestive enzymes and counter-adaptations in a specialist avian herbivore. Comparative Physiological Biology-B 185, 425-434.

Kohl KD, Stengel A and Dearing MD 2016b. Inoculation of tannin-degrading bacteria into novel hosts increases performance on tannin-rich diets. Environmental Microbiology 18, 1720-1729.

Kohl KD, Weiss RB, Cox J, Dale C and Denise Dearing M 2014. Gut microbes of mammalian herbivores facilitate intake of plant toxins. Ecology Letters 17 , 1238-1246.

Kooijman SALM and Metz JAJ 1984. On the dynamics of chemically stressed populations: the deduction of population consequences from effects on individuals. Ecotoxicology and Environmental Safety 8, 254-274.

Krizsan SJ, Mateos-Rivera A, Bertilsson S, Felton AM, Anttila A, Ramin M, Vaga $M$, Gidlund $\mathrm{H}$ and Huhtanen $\mathrm{P}$ 2018. An in vitro evaluation of browser and grazer fermentation efficiency and microbiota using European moose spring and summer foods. Ecology and Evolution 8, 4183-4196.

Lepist E-I and Ray AS 2017. Beyond drug-drug interactions: effects of transporter inhibition on endobiotics, nutrients and toxins. Expert Opinion on Drug Metabolism \& Toxicology 13, 1075-1087.
Li F, Ma K-S, Liang P-Z, Chen X-W, Liu Y and Gao X-W 2017. Transcriptional responses of detoxification genes to four plant allelochemicals in Aphis gossypii. Journal of Economic Entomology 110, 624-631.

Lim J, Kawamura K, Yoshitoshi R, Yayota M and Ogura S 2017. Hyperspectral assessment for legume contents and forage nutrient status in pasture. Journal of Integrated Field Science 14, 102-102.

Lindstedt SL and Schaeffer PJ 2002. Use of allometry in predicting anatomical and physiological parameters of mammals. Laboratory Animals 36, 1-19.

Liu R, Gourley SA, DeAngelis DL and Bryant JP 2012. Modeling the dynamics of woody plant-herbivore interactions with age-dependent toxicity. Journal of Mathematical Biology 65, 521-552.

Locke AE, Kahali B, Berndt SI, Justice AE, Pers TH, Day FR, Powell C, Vedantam S, Buchkovich ML and Yang J 2015. Genetic studies of body mass index yield new insights for obesity biology. Nature 518, 197.

MacArthur RH and Pianka ER 1966. On optimal use of a patchy environment. The American Naturalist 100, 603-609.

Macheras P and lliadis A 2006. Modeling in biopharmaceutics, pharmacokinetics, and pharmacodynamics. Interdisciplinary Applied Mathematics 30, 3-14.

Machovsky-Capuska GE, Priddel D, Leong PH, Jones P, Carlile N, Shannon L, Portelli D, McEwan A, Chaves AV and Raubenheimer D 2016. Coupling biologging with nutritional geometry to reveal novel insights into the foraging behaviour of a plunge-diving marine predator. New Zealand Journal of Marine and Freshwater Research 50, 418-432.

Mano $Y$, Sugiyama $Y$ and Ito $K$ 2015. Use of a physiologically based pharmacokinetic model for quantitative prediction of drug-drug interactions via CYP3A4 and estimation of the intestinal availability of CYP3A4 substrates. Journal of Pharmaceutical Sciences 104, 3183-3193.

Marsh KJ, Wallis IR, McLean S, Sorensen JS and Foley WJ 2006. Conflicting demands on detoxification pathways influence how common brushtail possums choose their diets. Ecology 87, 2103-2112.

McLean S, Boyle RR, Brandon S, Davies NW and Sorensen JS 2007. Pharmacokinetics of 1, 8-cineole, a dietary toxin, in the brushtail possum (Trichosurus vulpecula): significance for feeding. Xenobiotica 37, 903-922.

McLister JD, Sorensen JS and Dearing MD 2004. Effects of consumption of juniper (Juniperus monosperma) on cost of thermoregulation in the woodrats Neotoma albigula and Neotoma stephensi at different acclimation temperatures. Physiological and Biochemical Zoology 77, 305-312.

McShea WJ and Schwede G 1993. Variable acorn crops: responses of whitetailed deer and other mast consumers. Journal of Mammalogy 74, 999-1006.

Metcalf JC, Rose KE and Rees M 2003. Evolutionary demography of monocarpic perennials. Trends in Ecology \& Evolution 18, 471-480.

Moe SJ, Stelzer RS, Forman MR, Harpole WS, Daufresne T and Yoshida T 2005. Recent advances in ecological stoichiometry: insights for population and community ecology. Oikos 109, 29-39.

Moen R, Pastor J and Cohen Y 1997. A spatially explicit model of moose foraging and energetics. Ecology 78, 505-521.

Moore BD, Lawler IR, Wallis IR, Beale CM and Foley WJ 2010. Palatability mapping: a Koala's eye view of spatial variation in habitat quality. Ecology 91, 3165-3176.

Morden C-JC, Weladji RB, Ropstad E, Dahl E and Holand $\varnothing$ 2011. Use of faecal pellet size to differentiate age classes in female Svalbard reindeer Rangifer tarandus platyrhynchus. Wildlife Biology 17, 441-448.

Morris WF and Doak DF 2002. Quantitative conservation biology. Sinauer Associates Inc., Sunderland, MA, USA.

Moss R, Leckie F, Biggins A, Poole T, Baines D and Kortland K 2014. Impacts of human disturbance on capercaillie Tetrao urogallus distribution and demography in Scottish woodland. Wildlife Biology 20, 1-18.

Müller DW, Lackey LB, Streich WJ, Fickel J, Hatt J-M and Clauss M 2010. Mating system, feeding type and ex situ conservation effort determine life expectancy in captive ruminants. Proceedings of the Royal Society of London B: Biological Sciences 278, 2076-2080.

Muller EB, Nisbet RM, Kooijman SALM, Elser JJ and McCauley E 2001. Stoichiometric food quality and herbivore dynamics. Ecology Letters 4, 519-529.

Nisbet RM, Muller EB, Lika K and Kooijman S 2000. From molecules to ecosystems through dynamic energy budget models. Journal of Animal Ecology 69, 913-926.

Nowell SA, Ahn J, Rae JM, Scheys JO, Trovato A, Sweeney C, MacLeod SL, Kadlubar FF and Ambrosone CB 2005. Association of genetic variation in 
tamoxifen-metabolizing enzymes with overall survival and recurrence of disease in breast cancer patients. Breast Cancer Research and Treatment 91, 249-258. Owen-Smith N 2002. A metaphysiological modelling approach to stability in herbivore-vegetation systems. Ecological Modelling 149, 153-178.

Owen-Smith N 2004. Functional heterogeneity in resources within landscapes and herbivore population dynamics. Landscape Ecology 19, 761-771.

Panter KE, James LF and Gardner DR 1999. Lupines, poison-hemlock and Nicotiana spp: toxicity and teratogenicity in livestock. Journal of Natural Toxins 8, 117-134.

Parikh GL, Forbey JS, Robb B, Peterson RO, Vucetich LM and Vucetich JA 2017. The influence of plant defensive chemicals, diet composition, and winter severity on the nutritional condition of a free-ranging, generalist herbivore. Oikos 126, 196-203.

Parker KL, Barboza PS and Gillingham MP 2009. Nutrition integrates environmental responses of ungulates. Functional Ecology 23, 57-69.

Parker KL, Gillingham MP, Hanley TA and Robbins CT 1996. Foraging efficiency: energy expenditure versus energy gain in free-ranging black-tailed deer. Canadian Journal of Zoology 74, 442-450.

Pass GJ, McLean S, Stupans I and Davies N 2001. Microsomal metabolism of the terpene 1,8-cineole in the common brushtail possum (Trichosurus vulpecula), koala (Phascolarctos cinereus), rat and human. Xenobiotica 31, 205-221.

Patra AK and Saxena J 2011. Exploitation of dietary tannins to improve rumen metabolism and ruminant nutrition. Journal of the Science of Food and Agriculture 91, 24-37.

Pauli BP, Spaul RJ and Heath JA 2017. Forecasting disturbance effects on wildlife: tolerance does not mitigate effects of increased recreation on wildlands. Animal Conservation 20, 251-260.

Peters EJ and McLeod HL 2008. Ability of whole-genome SNP arrays to capture 'must have'pharmacogenomic variants. Pharmacogenomics 9, 1573-1577.

Peters SA, Jones CR, Ungell A-L and Hatley OJD 2016. Predicting drug extraction in the human gut wall: Assessing contributions from drug metabolizing enzymes and transporter proteins using preclinical models. Clinical Pharmacokinetics 55, 673-696.

Pontremoli C, Mozzi A, Forni D, Cagliani R, Pozzoli U, Menozzi G, Vertemara J, Bresolin N, Clerici M and Sironi M 2015. Natural selection at the brush-border: adaptations to carbohydrate diets in humans and other mammals. Genome Biology and Evolution 7, 2569-2584.

Pratchett D, Jones RJ and Syrch FX 1991. Use of DHP-degrading rumen bacteria to overcome toxicity in cattle grazing irrigated leucaena pasture. Tropical Grasslands 25, 268-274.

Pyke GH, Pulliam HR and Charnov EL 1977. Optimal foraging: a selective review of theory and tests. The Quarterly Review of Biology 52, 137-154.

Rao JS, Fan J, Kobetz E and Sussman D 2017. Something borrowed, something new: precise prediction of outcomes from diverse genomic profiles. In Mathematical and statistical applications in life sciences and engineering (ed. A Adhikari, M Adhikari and Y Chaubey), pp. 193-208. Springer, Singapore.

Raubenheimer D, Lee KP and Simpson SJ 2005. Does Bertrand's rule apply to macronutrients? Proceedings of the Royal Society of London B: Biological Sciences 272, 2429-2434.

Raubenheimer D, Machovsky-Capuska G, Felton AM and Simpson S 2014. Nutritional geometry: from insects to ruminants. Proceeding of the Australian Society of Animal Production 30, 32-36.

Raubenheimer D and Simpson SJ 1998. Nutrient transfer functions: the site of integration between feeding behaviour and nutritional physiology. Chemoecology 8, 61-68.

Raubenheimer D, Simpson SJ and Mayntz D 2009. Nutrition, ecology and nutritional ecology: toward an integrated framework. Functional Ecology 23, 4-16.

Rees M, Childs DZ and Ellner SP 2014. Building integral projection models: a user's guide. Journal of Animal Ecology 83, 528-545.

Reilly J 2002. Growth in the Sumatran elephant (Elephas maximus sumatranus) and age estimation based on dung diameter. Journal of Zoology 258, 205-213.

Revermann R, Schmid H, Zbinden N, Spaar R and Schröder B 2012. Habitat at the mountain tops: how long can Rock Ptarmigan (Lagopus muta helvetica) survive rapid climate change in the Swiss Alps? A multi-scale approach. Journal of Ornithology 153, 891-905.

Robbins CT, Hagerman AE, Austin PJ, McArthur C and Hanley TA 1991. Variation in mammalian physiological responses to a condensed tannin and its ecological implications. Journal of Mammalogy 72, 480-486.
Rode KD and Robbins CT 2000. Why bears consume mixed diets during fruit abundance. Canadian Journal of Zoology 78, 1640-1645.

Rothman JM, Raubenheimer D and Chapman CA 2011. Nutritional geometry: gorillas prioritize non-protein energy while consuming surplus protein. Biology Letters 7, 847-849.

Ruktanonchai NW, DeLeenheer P, Tatem AJ, Alegana VA, Caughlin TT, ErbachSchoenberg E zu, Lourenço C, Ruktanonchai CW and Smith DL 2016. Identifying malaria transmission foci for elimination using human mobility data. PLoS Computational Biology 12, e1004846.

Sager JE, Yu J, Raguenau-Majlessi I and Isoherranen N 2015. Physiologically based pharmacokinetic (PBPK) modeling and simulation approaches: a systematic review of published models, applications and model verification. Drug Metabolism and Disposition 43, 1823-1837.

Saltelli A, Ratto M, Tarantola S and Campolongo F 2006. Sensitivity analysis practices: strategies for model-based inference. Reliability Engineering \& System Safety 91, 1109-1125.

Santos $M$, Niemi M, Hiratsuka $M$, Kumondai $M$, Ingelman-Sundberg $M$, Lauschke VM and Rodríguez-Antona C 2018. Novel copy-number variations in pharmacogenes contribute to interindividual differences in drug pharmacokinetics. Genetics in Medicine 20, 622-629.

Sauvé DG and Côté SD 2006. Is winter diet quality related to body condition of white-tailed deer (Odocoileus virginianus)? An experiment using urine profiles. Canadian Journal of Zoology 84, 1003-1010.

Schilderink R, Verseijden C and de Jonge WJ 2013. Dietary inhibitors of histone deacetylases in intestinal immunity and homeostasis. Frontiers in Immunology 4, 226 .

Schoener TW 1971. Theory of feeding strategies. Annual Review of Ecology and Systematics 2, 369-404.

Schultz A, Barbosa-da-Silva S, Aguila MB and Mandarim-de-Lacerda CA 2015. Differences and similarities in hepatic lipogenesis, gluconeogenesis and oxidative imbalance in mice fed diets rich in fructose or sucrose. Food \& Function 6, 1684-1691.

Servello FA and Schneider JW 2000. Evaluation of urinary indices of nutritional status for white-tailed deer: tests with winter browse diets. The Journal of Wildlife Management 64, 137-145.

Shipley LA, Davis EM, Felicetti LA, McLean S and Forbey JS 2012. Mechanisms for eliminating monoterpenes of sagebrush by specialist and generalist rabbits. Journal of Chemical Ecology 38, 1178-1189.

Shipley LA, Forbey JS and Moore BD 2009. Revisiting the dietary niche: when is a mammalian herbivore a specialist? Integrative and Comparative Biology 49, 274-290.

Shipley LA, Illius AW, Danell K, Hobbs NT and Spalinger DE 1999. Predicting bite size selection of mammalian herbivores: a test of a general model of diet optimization. Oikos 84, 55-68.

Sibly RM, Grimm V, Martin BT, Johnston ASA, Kułakowska K, Topping CJ, Calow P, Nabe-Nielsen J, Thorbek P and DeAngelis DL 2013. Representing the acquisition and use of energy by individuals in agent-based models of animal populations. Methods in Ecology and Evolution 4, 151-161.

Simpson SJ, Batley R and Raubenheimer D 2003. Geometric analysis of macronutrient intake in humans: the power of protein? Appetite 41, 123-140.

Simpson SJ, Le Couteur DG, James DE, George J, Gunton JE, Solon-Biet SM and Raubenheimer D 2017. The geometric framework for nutrition as a tool in precision medicine. Nutrition and Healthy Aging 4, 217-226.

Simpson SJ and Raubenheimer D 1993. A multi-level analysis of feeding behaviour: the geometry of nutritional decisions. Philosophical Transactions of the Royal Society of London. Series B 342, 381-402.

Simpson SJ and Raubenheimer D 2001. The geometric analysis of nutrient-allelochemical interactions: a case study using locusts. Ecology 82, 422-439.

Simpson SJ and Raubenheimer D 2005. Obesity: the protein leverage hypothesis. Obesity Reviews 6, 133-142.

Simpson SJ and Raubenheimer D 2012. The nature of nutrition: a unifying framework from animal adaptation to human obesity. Princeton University Press, Princeton, NJ, USA.

Smallegange IM, Caswell H, Toorians MEM and Roos AM de 2017. Mechanistic description of population dynamics using dynamic energy budget theory incorporated into integral projection models. Methods in Ecology and Evolution 8, 146-154. 
Forbey, Liu, Caughlin, Matocq, Vucetich, Kohl, Dearing and Felton

Smith FA, Betancourt JL and Brown JH 1995. Evolution of body size in the woodrat over the past 25,000 years of climate change. Science 270, 2012-2014.

Smith-Ramesh LM, Rosenblatt AE and Schmitz OJ 2017. Multivariate climate change can favor large herbivore body size in food webs. The American Naturalist 191, 333-342.

Snoeck S, Greenhalgh R, Tirry L, Clark RM, Leeuwen TV and Dermauw W 2017. The effect of insecticide synergist treatment on genome-wide gene expression in a polyphagous pest. Scientific Reports 7, 13440.

Solon-Biet SM, McMahon AC, Ballard JWO, Ruohonen K, Wu LE, Cogger VC, Warren A, Huang X, Pichaud N, Melvin RG, Gokarn R, Khalil M, Turner N, Cooney GJ, Sinclair DA, Raubenheimer D, Le Couteur DG and Simpson SJ 2014. The ratio of macronutrients, not caloric intake, dictates cardiometabolic health, aging, and longevity in ad libitum-fed mice. Cell Metabolism 19, 418-430.

Soppela P, Nieminen M and Saarela S 1992. Water intake and its thermal energy cost in reindeer fed lichen or various protein rations during winter. Acta Physiologica 145, 65-73.

Sørensen A, Mayntz D, Raubenheimer D and Simpson SJ 2008. Protein-leverage in mice: the geometry of macronutrient balancing and consequences for fat deposition. Obesity $16,566-571$.

Sorensen J and Dearing M 2003. Elimination of plant toxins by herbivorous woodrats: revisiting an explanation for dietary specialization in mammalian herbivores. Oecologia 134, 88-94.

Sorensen JS, Heward E and Dearing MD 2005a. Plant secondary metabolites alter the feeding patterns of a mammalian herbivore (Neotoma lepida). Oecologia 146, 415-422.

Sorensen JS, McLister JD and Dearing MD 2005b. Plant secondary metabolites compromise the energy budgets of specialist and generalist mammalian herbivores. Ecology 86, 125-139.

Sorensen JS, McLister JD and Dearing MD 2005c. Novel plant secondary metabolites impact dietary specialists more than generalists (Neotoma spp). Ecology 86, 140-154.

Sorensen JS, Skopec MM and Dearing MD 2006. Application of pharmacological approaches to plant-mammal interactions. Journal of Chemical Ecology 32, 1229-1246.

Sorensen JS, Turnbull CA and Dearing MD 2004. A specialist herbivore (Neotoma stephensi) absorbs fewer plant toxins than does a generalist (Neotoma albigula). Physiological and Biochemical Zoology 77, 139-148.

Spalinger DE, Collins WB, Hanley TA, Cassara NE and Carnahan AM 2010. The impact of tannins on protein, dry matter, and energy digestion in moose (Alces alces). Canadian Journal of Zoology 88, 977-987.

Stolter C, Ball JP and Julkunen-Tiitto R 2013. Seasonal differences in the relative importance of specific phenolics and twig morphology result in contrasting patterns of foraging by a generalist herbivore. Canadian Journal of Zoology 91, 338-347.

Stolter C, Julkunen-Tiitto R and Ganzhorn JU 2006. Application of near infrared reflectance spectroscopy (NIRS) to assess some properties of a sub-arctic ecosystem. Basic and Applied Ecology 7, 167-187.

Svartström 0, Alneberg J, Terrapon N, Lombard V, de Bruijn I, Malmsten J, Dalin A-M, Muller EE, Shah P and Wilmes P 2017. Ninety-nine de novo assembled genomes from the moose (Alces alces) rumen microbiome provide new insights into microbial plant biomass degradation. The ISME Journal 11, 2538-2551.

Tay-Sontheimer J, Shireman LM, Beyer RP, Senn T, Witten D, Pearce RE, Gaedigk A, Gana Fomban CL, Lutz JD and Isoherranen N 2014. Detection of an endogenous urinary biomarker associated with CYP2D6 activity using global metabolomics. Pharmacogenomics 15, 1947-1962.

Teorell T 1937a. Kinetics of distribution of substances administered to the body, I: the extravascular modes of administration. Archives Internationales de Pharmacodynamie et de Therapie 57, 205-225.

Teorell T 1937b. Kinetics of distribution of substances administered to the body, II: the intravascular modes of administration. Archives Internationales de Pharmacodynamie et de Therapie 57, 226-240.

Ting Y, Zhao Q, Xia C and Huang Q 2015. Using in vitro and in vivo models to evaluate the oral bioavailability of nutraceuticals. Journal of Agricultural and Food Chemistry 63, 1332-1338.

Torregrossa AM, Azzara AV and Dearing MD 2012. Testing the diet-breadth trade-off hypothesis: differential regulation of novel plant secondary compounds by a specialist and a generalist herbivore. Oecologia 168, 711-718.
Torregrossa A-M and Dearing MD 2009. Nutritional toxicology of mammals: regulated intake of plant secondary compounds. Functional Ecology 23, 48-56. Torrens PM 2010. Agent-based models and the spatial sciences. Geography Compass 4, 428-448.

Tsamandouras N, Rostami-Hodjegan A and Aarons L 2015. Combining the 'bottom up' and 'top down'approaches in pharmacokinetic modelling: fitting PBPK models to observed clinical data. British Journal of Clinical Pharmacology 79, 48-55.

Tucci SA, Boyland EJ and Halford JC 2010. The role of lipid and carbohydrate digestive enzyme inhibitors in the management of obesity: a review of current and emerging therapeutic agents. Diabetes, Metabolic Syndrome and Obesity: Targets and Therapy 3, 125

Turnbaugh PJ, Ley RE, Mahowald MA, Magrini V, Mardis ER and Gordon JI 2006. An obesity-associated gut microbiome with increased capacity for energy harvest. Nature 444, 1027-1031.

Ulappa AC, Kelsey RG, Frye GG, Rachlow JL, Shipley LA, Bond L, Pu X and Forbey JS 2014. Plant protein and secondary metabolites influence diet selection in a mammalian specialist herbivore. Journal of Mammalogy 95, 834-842.

Van Duynhoven J, Vaughan EE, Jacobs DM, Kemperman RA, Van Velzen EJ, Gross G, Roger LC, Possemiers S, Smilde AK and Doré J 2011. Metabolic fate of polyphenols in the human superorganism. Proceedings of the National Academy of Sciences 108, 4531-4538.

Villalba JJ and Provenza FD 2005. Foraging in chemically diverse environments: energy, protein, and alternative foods influence ingestion of plant secondary metabolites by lambs. Journal of Chemical Ecology 31, 123-138.

Wam HK, Felton AM, Stolter C, Nybakken L and Hjeljord 0 2018. Moose selecting for specific nutritional composition of birch places limits on food acceptability. Ecology and Evolution 8, 1117-1130.

Wang E, Zaman N, Mcgee S, Milanese J-S, Masoudi-Nejad A and O'ConnorMcCourt M 2015. Predictive genomics: a cancer hallmark network framework for predicting tumor clinical phenotypes using genome sequencing data. Seminars in Cancer Biology 30, 4-12.

West GC and Meng MS 1968. Seasonal changes in body weight and fat and the relation of fatty acid composition to diet in the Willow Ptarmigan. The Wilson Bulletin 80, 426-441.

Whitcomb DC and Lowe ME 2007. Human pancreatic digestive enzymes. Digestive Diseases and Sciences 52, 1-17.

Wiggins NL, McArthur C, McLean S and Boyle R 2003. Effects of two plant secondary metabolites, cineole and gallic acid, on nightly feeding patterns of the common brushtail possum. Journal of Chemical Ecology 29, 1447-1464.

Wikelski M and Cooke SJ 2006. Conservation physiology. Trends in Ecology \& Evolution 21, 38-46.

Wilson ID and Nicholson JK 2017. Gut microbiome interactions with drug metabolism, efficacy, and toxicity. Translational Research 179, 204-222.

Wing BR and Messmer TA 2016. Impact of sagebrush nutrients and monoterpenes on greater sage-grouse vital rates. Human-Wildlife Interactions 10, 157-168.

Wobeser G and Runge W 1975. Rumen overload and rumenitis in whitetailed deer. The Journal of Wildlife Management 39, 596-600.

Yu L, Wang Z, Huang M, Li Y, Zeng K, Lei J, Hu H, Chen B, Lu J, Xie W and Zeng S 2016. Evodia alkaloids suppress gluconeogenesis and lipogenesis by activating the constitutive androstane receptor. Biochimica Et Biophysica Acta-Gene Regulatory Mechanisms 1859, 1100-1111.

Yule I, Pullanagari R, Irwin M, McVeagh P, Kereszturi G, White M and Manning M 2015. Mapping nutrient concentration in pasture using hyperspectral imaging. Journal of New Zealand Grasslands 77, 47-50.

Zhao P, Zhang L, Grillo JA, Liu Q, Bullock JM, Moon YJ, Song P, Brar SS, Madabushi R, Wu TC, Booth BP, Rahman NA, Reynolds KS, Berglund EG, Lesko $\mathrm{LJ}$ and Huang S-M 2011. Applications of physiologically based pharmacokinetic (PBPK) modeling and simulation during regulatory review. Clinical Pharmacology \& Therapeutics 89, 259-267.

Zhao S, Zheng P, Dong S, Zhan X, Wu Q, Guo X, Hu Y, He W, Zhang S and Fan W 2013. Whole-genome sequencing of giant pandas provides insights into demographic history and local adaptation. Nature Genetics 45, 67.

Zipkin EF and Saunders SP 2018. Synthesizing multiple data types for biological conservation using integrated population models. Biological Conservation 217, 240-250. 